\title{
V. Vertreibung und Integration als Lebens-Erfahrung
}




\title{
Ute Schmidt \\ „Drei- oder viermal im Leben neu anfangen \\ zu müssen ...“-
}

\author{
Beobachtungen zur ländlichen Vertriebenenintegration \\ in mecklenburgischen „Bessarabier-Dörfern“
}

Dieser Beitrag basiert auf Teilergebnissen eines Forschungsprojekts, das die Integration der Bessarabiendeutschen in der Bundesrepublik und der früheren DDR zum Thema hat ${ }^{1}$. Zur Anlage dieses Projekts, seinen Fragestellungen und seiner Vorgehensweise sind einige Vorbemerkungen nötig, die den Forschungskontext umreißen, in dem es entstanden ist.

\section{Zum Forschungskontext des "Bessarabien-Projekts" ${ }^{\text {"2 }}$}

Seit Mitte der achtziger Jahre fand in der Flüchtlingsforschung ein Perspektivenwechsel statt. In einem Diskurs westdeutscher Sozialwissenschaftler verschiedener Disziplinen wurde jetzt ein stärker interdisziplinärer Zuschnitt bzw. die Neuakzentuierung der Flüchtlingsforschung als eine mit modernen sozialwissenschaftlichen Methoden und Fragestellungen operierende Integrationsforschung formuliert ${ }^{3}$. Das neuerliche Interesse an dieser Thematik war zum einen Ausdruck einer veränderten gesellschaftspolitischen Problemlage. So bedeutete die Zuwanderung von ausländischen Arbeitern, Aussiedlern und Asylbewerbern für die Bundesrepublik in den achtziger Jahren eine Herausforderung, die sich in einer intensivierten Debatte über Integration, Assimilation und kulturelle Identität niederschlug. Das wachsende Interesse an der Flüchtlingsproblematik signalisierte zugleich, daß zeitbedingte und aus einem politischen Generationskonflikt der fünfziger und sechziger Jahre herrührende Blockierungen in der zeitgeschichtlichen Forschung allmählich überwunden wurden. In den Arbeiten jüngerer Sozial- und Zeithistoriker, die sich seit den sechziger Jahren verstärkt mit der Vorgeschichte und den Entstehungsbedingungen der Bundesrepublik befaßt hatten, war die Problematik von Flucht, Vertreibung und Eingliederung weitgehend ausgeblendet worden. Diese Optik veränderte sich: Die Millionen von Vertriebenen und Flüchtlingen werden nun auch als Opfer der Folgen der nationalsozialistischen Gewaltherrschaft über Europa gesehen und nicht mehr nur pauschal als Anhänger rechtslastiger Positionen einge-

1 Das Projekt wurde 1992-1995 am Zentralinstitut für Sozialwissenschaftliche Forschung der Freien Universität Berlin durchgeführt und vom Bundesministerium des Innern gefördert.

2 Dieser Abschnitt bezieht sich auf einen Vortrag, den ich auf der Tagung „50 Jahre Flucht und Vertreibung" am 22. 9. 1995 in Magdeburg gehalten habe.

${ }^{3}$ Vgl. hierzu Schulze u. a., Flüchtlinge und Vertriebene. 
ordnet ${ }^{4}$. Die Schrecken von Flucht, Vertreibung und „ethnischer Säuberung“ angesichts des Krieges im ehemaligen Jugoslawien haben dem Thema in den neunziger Jahren wieder eine neue Aktualität verschafft.

Mit der Einbeziehung von Fragestellungen und methodischen Ansätzen aus der Sozialgeschichte, der Lokal-, Regional- und Alltagsgeschichtsforschung, der empirischen Kulturwissenschaft und der Migrationsforschung erweiterten sich die Untersuchungsperspektiven der Flüchtlingsforschung über die primär ökonomisch-sozialen Aspekte der Eingliederung und die Analyse des Verwaltungshandelns hinaus auf die Lebenssituationen und Bewältigungsstrategien der Flüchtlinge sowie auf die Sozialbeziehungen zwischen den Zuwanderern und den Einheimischen. „Integration“ bezeichnet nicht die bloß einseitige Anpassung von "Neubürgern“ an die Normen einer im großen und ganzen konsolidierten Aufnahmegesellschaft, sondern einen wechselseitigen Akkulturationsprozeß, der sich unter verschiedenartigen und sich verändernden Bedingungen vollzieht. Ein stärker soziologisch akzentuiertes Forschungskonzept bezieht auch die Dynamik des sozialen Wandels mit ein, die vielerorts bereits vor dem Ende des Zweiten Weltkrieges eingesetzt hatte.

\section{Fragestellungen und Methode des "Bessarabien-Projekts"}

Das Bessarabien-Projekt versteht sich als eine Art Pilotstudie, in der es um die Anwendungs- und Weiterentwicklungsmöglichkeiten eines fächerübergreifenden Forschungsansatzes geht. Es setzt vor allem an drei Defiziten der bisherigen Flüchtlingsforschung an:

- Die Analyse der Integrationsverläufe bricht hier nicht mit der sogenannten „Erlebnisgeneration" ab, sondern bezieht auch die zweite und dritte Flüchtlingsgeneration mit ein, denn der Erfolg oder das Mißlingen von Integrationsprozessen erweist sich erst in der Generationenabfolge ${ }^{5}$. Sie will überdies Differenzierungen bei den Zuwanderern und unterschiedliche Integrationsverläufe herausarbeiten. Daher sollen die konkreten Konstellationen, in denen Aufnahme und Akkulturation stattfanden, genauer betrachtet, verglichen und in ihren längerfristigen Auswirkungen untersucht werden.

- Das Forschungsinteresse gilt nicht nur sozioökonomischen und politischen Integrationsfaktoren, sondern auch den in den früheren Siedlungsgebieten erworbenen kulturellen Prägungen. Mentalitäten, Verhaltensdispositionen und Deutungsmuster werden als relevante, den Akkulturationsprozeß beeinflussende Variablen betrachtet und das hierin enthaltene Potential zur Strukturierung einer veränderten und sich verändernden Umwelt analysiert. Interessant ist, ob und in welcher Weise solche Prägungen auf die nächste Generation transferiert werden. Mit Bezug auf Pierre Bourdieu verwende ich hier den Begriff des "kulturellen“ bzw. des „sozialen Kapitals“ als analytische Kategorie, mit der über Zeit akkumulierte Fähigkeiten immaterieller Art bezeichnet werden $^{6}$.

- Drittens gehe ich von der These aus, daß die jeweils unterschiedlichen Wanderungsbedingungen und Fluchterfahrungen systematisch in die Analyse von Integrationsprozessen einzubeziehen sind, da sie die Integrationsbereitschaft und -chancen von Vertriebenen und Flüchtlingen im Nachkriegsdeutschland mitgeprägt haben.

${ }^{4}$ Vgl. Grebing, in: ebenda, S. 2.

${ }^{5}$ Vgl. Lüttinger, Der Mythos der schnellen Integration.

${ }^{6}$ Vgl. Bourdieu, Ökonomisches Kapital. 
In einem Längsschnitt wird nun an einem konkreten Beispiel - in einer Fallstudie über die Bessarabiendeutschen - geprüft, welche Relevanz solchen Faktoren bei der Analyse von Akkulturations- und Integrationsprozessen beizumessen ist ${ }^{7}$. Es wird untersucht, ob und wie lange solche Präformierungen in der sich herausbildenden bundesrepublikanischen bzw. DDR-Nachkriegsgesellschaft weiterwirkten, wie sie sich in der Interaktion mit den Einheimischen wandelten und welche Bedeutung sie noch für die Situationsdefinition der nachwachsenden Generation haben.

Die Aufbereitung der Informationen aus den Interviews zeigt, daß der „Mythos der schnellen Integration" ${ }^{8}$ einer differenzierten Betrachtungsweise unterzogen werden muß. Denn bei Integrationsvorgängen spielen nicht nur die äußeren Konstellationen (Hemmnisse wie Chancen), in denen Aufnahme und Akkulturation stattfanden, eine Rolle, sondern auch Lebensalter, Geschlecht, früherer Status, Ausbildung, familiäre Situation, Verhaltens- und Orientierungsmuster. Was für die einen Deklassierung, Statusverlust oder Abbruch von Lebensperspektiven bedeutete, konnte anderen bis dahin ungeahnte berufliche Chancen und Lebenswege eröffnen. Im übrigen gab es auch Formen der Nicht-Integration, die zu Anomie oder Suiziden führten. Integration ist nicht immer nur eine Erfolgsgeschichte.

Die Befragung der zweiten Generation ergänzt die Sichtweise der Eltern und Großeltern um eine andere Perspektive. Die Ergebnisse der Untersuchung zeigen, daß tradierte Normen und Verhaltensmuster für die Jüngeren noch eine Bedeutung haben, daß sie aber stärker reflektiert und problematisiert werden. Auch die Identitätsfrage ist hier ein noch immer aktuelles Thema.

\section{Zur Auswabl der Fallstudie: Warum die Bessarabiendeutschen?}

Im Vergleich zu anderen - etwa den Schlesiern, den Pommern oder den Sudetendeutschen - stellen die Bessarabiendeutschen nur eine kleine Flüchtlingsgruppe dar'. Die Überschaubarkeit des Personenkreises ist jedoch gerade für eine empirische Längsschnittstudie von erheblichem Vorteil. Die Wanderungs- und Siedlungsgeschichte ist sehr gut dokumentiert. Sie weist übrigens mehrere Besonderheiten auf, die für die Untersuchung von Integrationsbedingungen, -chancen und -verläufen interessant sind:

1. Die Siedlungsgeschichte der Bessarabiendeutschen in Südrußland (seit 1918 gehörte das Territorium zu Rumänien) ist relativ kurz; sie umfaßt nur ca. 125 Jahre, also etwa fünf Generationen. Zwar waren die persönlichen Rückbezüge zur „Urheimat“ längst abgerissen, sie waren aber über Kirchen- und Gemeindebücher zumeist noch gut rekonstruierbar und wurden nach dem Ersten Weltkrieg wieder intensiviert. Die

${ }^{7}$ Materialbasis für das Projekt sind: (1) Aktenbestände verschiedener Provenienzen in staatlichen, städtischen und Landesarchiven; Bestände aus Verbands-, Kirchen- und Privatarchiven; Literatur, Zeitschriften und Presse, Tondokumente aus der frühen Nachkriegszeit, Fotosammlungen, Nachlässe usw. (2) Lebensgeschichtliche Interviews. Dafür wurden Interviewpartner aus je fünf Familien (in drei Generationen) aus fünf bessarabischen Herkunftsorten, die nach bestimmten Strukturmerkmalen unterschiedenen wurden, ausgewählt, (3) Ein Fragebogen zur Erfassung der regionalen und sozialen Mobilität.

${ }^{8}$ Lüttinger, Der Mythos der schnellen Integration.

9 Sie umfaßte 1940 knapp 94000 Personen; mehr als 10000 von ihnen, also über $10 \%$, haben die Flucht nicht überlebt. Vor allem Frauen, Kinder und alte Leute, sind durch die Folgen unmittelbarer Gewalt, Verschleppung, Hunger und Zwangsarbeit ums Leben gekommen; mindestens 6000 Männer waren als Soldaten im Krieg gefallen oder vermißt gemeldet. 
NS-Sippenforschung und die Ahnenpässe gaben diesen Nachforschungen weiteren Auftrieb.

2. Ein großer Teil der Bessarabiendeutschen stammte aus Süd- und Südwestdeutschland - einer Region, in die es nach 1945 die meisten bessarabiendeutschen Flüchtlinge wieder hinzog. Hingegen stammten die sogenannten "Kaschuben“ aus Mecklenburg, Pommern und Westpreußen und sprachen plattdeutsch. Auch in Mecklenburg sind nach der Flucht viele Bessarabier geblieben und auf Bodenreform-Land ansässig geworden; andere wanderten, sofern dies möglich war, nach Westen weiter. Einen Teil der Bessarabiendeutschen verschlug es in die britische Zone, insbesondere nach Niedersachsen. So verteilten sich die Bessarabiendeutschen nach 1945 relativ gleichmäßig in eine süd-, nord- und ostdeutsche Gruppe, die jeweils unterschiedliche Bezüge und Aufnahmebedingungen vorfand. Eine vergleichende Analyse der verschiedenen Integrationsbedingungen bietet sich an.

3. Das kulturelle Milieu der Bessarabiendeutschen und ihre Mentalität waren durch Einflüsse geprägt, die aus der Wanderungsgeschichte herrühren ${ }^{10}$. Die spezifische Ausformung dieses protestantisch-pietistischen Milieus, seiner Ethik und Arbeitsauffassung, war nicht zuletzt auch das Ergebnis eines kirchlich-kulturellen Disziplinierungsprozesses, der sich im 19. Jahrhundert vollzog und dessen Prägekraft auch nach 1945 noch spürbar war. Der sprichwörtliche "Pioniergeist" der Bessarabiendeutschen bezieht sich zudem darauf, daß die zaristische Regierung den Neusiedlern in Südrußland die Funktion eines modernisierenden Elements in der stagnierenden Agrargesellschaft Rußlands zugedacht hatte. Er zählt mit zu den Selbstbildern, die den Bessarabiendeutschen nach 1945 die Integration erleichtern halfen.

4. Die Bessarabiendeutschen sind gleichermaßen „Umsiedler" wie „Flüchtlinge“. Zwar gelangten sie, wie andere Flüchtlinge auch, 1945 auf der Flucht vor der Roten Armee in den Westen. Sie waren aber bereits 1940 - entsprechend der 1939 im Geheimen Zusatzprotokoll zum Hitler-Stalin Pakt vereinbarten Aufteilung der Interessensphären in Osteuropa - im Herbst 1940 aus ihrer Heimat ausgesiedelt und (nach mehreren Zwischenstationen und Lageraufenthalten im damaligen "Altreich“ und im besetzten Polen) im sogenannten "Warthegau“ und in „Danzig-Westpreußen“ angesiedelt worden. Im Begriff des "Umsiedlers" ist also in diesem Fall - im Unterschied zum Sprachgebrauch der DDR, der alle Flüchtlinge und Vertriebenen darunter faßte und deren Schicksal damit entdramatisierte - noch eine weitere Erfahrungsdimension enthalten. So mußten die bessarabiendeutschen Umsiedler - wie auch die anderen Umgesiedelten aus der Bukowina

10 Vgl. dazu Schmidt, Zweifacher Heimatverlust. - In Württemberg hatte nach der Wende zum 19. Jahrhundert eine pietistische Erweckungsbewegung, die sich gegen die vom aufklärerisch-rationalistischen Geist bestimmten Neuerungen in der evangelischen Kirche richtete, starken Auftrieb erhalten. Ein Teil ihrer Anhänger zog zum Kaukasus, wo die Wiederkehr Christi erwartet wurde. Erschöpfung und Epidemien bewogen jedoch eine Gruppe von ihnen, ihre Reise abzubrechen und sich in der Provinz Bessarabien niederzulassen, die nach dem Frieden von Bukarest 1812 von den Türken an Rußland abgetreten und von den russichen Behörden mit Kolonisten besiedelt wurde. $\mathrm{Zu}$ dieser chiliastischen Bewegung stießen Anhänger des katholischen Pfarrers Ignaz Lindl, der in Bayern in Konflikt mit der ultramontanen Kirchenführung geraten war und ebenfalls in Rußland Zuflucht suchte. Zusammen mit dem schwäbischen Kaufmann Christian F. Werner gründete Lindl seit 1822 mehrere Mutterkolonien in Bessarabien, in denen anfangs noch Gütergemeinschaft und ein stark religiös bestimmtes Gemeinschaftsleben praktiziert wurde. Die Kolonie Sarata wurde zum Zentrum des geistlichen Lebens und eines schon früh ausgebauten, kirchlich bestimmten Bildungswesens. 
und der Dobrudscha, dem Baltikum, Wolhynien, und Galizien - 1945 einen doppelten Verlust verarbeiten. Für sie gab es - im Unterschied zu anderen Flüchtlingen und Vertriebenen - nach dem Ende des verlorenen Krieges keinerlei Hoffnung auf eine Rückkehr in ihre Heimat mehr ${ }^{11}$. Gerade weil die Bessarabiendeutschen ihre Lage nicht als provisorisch betrachteten, sondern den endgültigen Einschnitt sahen, wollten sie möglichst rasch mit dem Aufbau einer neuen Existenz beginnen ${ }^{12}$.

5. Die Umsiedlung war von der NS-Regierung als „Heimführung ins Reich“ propagiert und von der Mehrheit der Bessarabiendeutschen auch als Rettungsaktion vor dem drohenden Bolschewismus betrachtet worden. Allerdings hatten die Erfahrungen in dieser Zeit manche Illusionen über das - idealisierte - nationalsozialistische Deutschland zunichte gemacht. Großfamilien und Dorfgemeinschaften wurden auseinandergerissen, religiöse Grundorientierungen und das Rechtsgefühl massiv in Frage gestellt; traditionelle Besitz- und Autoritätsstrukturen gerieten ins Wanken. Diese Erfahrungen bedeuteten noch vor dem Fluchterlebnis einen ersten massiven Kontinuitätsbruch. Die Verarbeitung der Eindrücke in dieser Phase und die Frage nach ihren politisch-psychologischen wie sozialkulturellen Auswirkungen für die Nachkriegszeit ist (auch für andere betroffene Flüchtlingsgruppen) bisher kaum untersucht worden.

Aus all dem folgt, daß die Bessarabiendeutschen aufgrund ihrer Vorgeschichte im Vergleich zu Flüchtlingen aus anderen Herkunftsgebieten nach 1945 relativ günstige Integrationsvoraussetzungen mitbrachten. Die gilt besonders für diejenigen, die in den süd- und südwestdeutschen Raum gelangten; denn, trotz mancher Ungleichzeitigkeiten, waren ihnen hier Dialekt, Religion und Volkskultur nicht fremd. Ihnen half zudem die Vorstellung, nach einer langen historischen Reise wieder in ihre „Urheimat“ zurückzukehren, wo sie nicht mehr Minderheit wären, sondern als Deutsche unter Deutschen (bzw. als Schwaben unter Schwaben) leben könnten.

Trotz dieser historisch-kulturellen Nähe zwischen Schwaben und Bessarabiendeutschen war in den verschiedenen Phasen des Integrationsprozesses freilich selbst hier eine „Empathie“, d. h. die Bereitschaft und Fähigkeit, sich in Einstellungen anderer Menschen einzufühlen, auf beiden Seiten nicht immer vorhanden. Das ist nicht verwunderlich, denn Integrationsvorgänge sind auch im günstigen Fall naturgemäß von vielen sozialen Konflikten durchzogen, vor allem dann, wenn die Güter (Nahrungsmittel, Wohnungen, Arbeits- und Ausbildungsplätze), die im Aufnahmeland zur Verfügung stehen bzw. verteilt werden können, knapp sind. Statusinkonsistenzen können im übrigen gera-

${ }^{11}$ In der „Deutsch-sowjetrussischen Vereinbarung über die Umsiedlung der Deutschen aus Bessarabien und der Nordbukowina" vom 5. September 1940 war vereinbart worden, daß die Umsiedlung bis zum 15. November 1940 abgeschlossen sein müsse. Den Umsiedlern wurde zugesichert, daß sie für ihr zurückgelassenes Vermögen, das nun in die Verfügungsgewalt der UdSSR überging, entschädigt würden; die Wertsumme sollte zwischen dem Deutschen Reich und der UdSSR verrechnet und in zehn Jahresraten transferiert werden. Eine Realentschädigung in den von der Deutschen Wehrmacht eroberten polnischen Gebieten, in denen die Umsiedler seit 1941 angesiedelt wurden, war während des Krieges nicht vorgesehen. Nach dem Zusammenbruch 1945 war völlig unklar, ob es überhaupt eine irgendwie geartete Entschädigung geben würde. Die Hilfskomitees der Bessarabiendeutschen warnten ihre Landsleute vor überzogenen Hoffnungen, bestanden jedoch darauf, daß der von der früheren Reichsregierung verbürgte Rechtsanspruch auf Entschädigung auch von der Bundesrepublik anerkannt wurde. Vgl. Schmidt, „Arbeiten - und nicht verzweifeln...".

12 In diese Richtung argumentierten auch die bessarabischen Pfarrer und Prediger, die ihre Autorität und interpretative Leitfunktion behalten hatten. 
de bei Nähe als besonders gravierend empfunden werden, wenn entsprechende Erwartungen enttäuscht werden.

Ein weiteres Problem kam hinzu: Die Eingliederung in die expandierende westdeutsche Industriegesellschaft, in die die Rückwanderer aus Bessarabien sozusagen hineinkatapultiert wurden, verlangte vom Gros der einst bäuerlichen Bevölkerung eine vollständige berufliche Neuorientierung und eine extreme Anpassungsleistung. Im Unterschied zur Umsiedlung, bei der die Bessarabiendeutschen zwar zerstreut wurden, die Erhaltung ihrer Berufsstruktur jedoch im Interesse der NS-Siedlungspolitik gelegen hatte, verloren sie nach der Flucht 1945 ihre Identität als Bauernvolk ${ }^{13}$. Während der relativ kleine Teil der Akademiker (als Beamte, Pfarrer, Lehrer) relativ schnell wieder in die alten Berufe zurückfand, konnten von der großen Gruppe der Bauern in den Westzonen nur wenige als selbständige Landwirte Fuß fassen. In der britischen Zone gab es verschiedene Siedlungsprojekte auf Staatsgelände, dennoch blieb die Zahl derer, die einen Hof kaufen oder pachten konnten, sehr gering. Noch hoffte man auf eine Bodenreform und diskutierte im übrigen leidenschaftlich über eine Auswanderung nach Überse ${ }^{14}$. Die Berichte aus Württemberg zeigten, daß kaum 10 Prozent der früheren Bauern in ihrem Beruf tätig waren und auch von ihnen saßen viele auf $Z$ wergwirtschaften. Die meisten der ehemals selbständigen Bauern und Landarbeiter, die sich nach Kriegsende zunächst als Hilfskräfte auf dem Lande verdingt hatten, wanderten schon bald in die Industrie ab. Gründe dafür waren: die schlechte Bezahlung der Landarbeiter, die Aussichtslosigkeit, selbst einen Hof erwerben zu können, nicht zuletzt auch die häufig ungerechte Behandlung und Ausbeutung der Flüchtlinge. Die Erfahrung von Dequalifizierung und die Umkehrung gesellschaftlicher Statuspositionen führte gerade im Bereich der Landwirtschaft zu oft unüberbrückbaren Spannungen. Die vielseitige handwerkliche Qualifikation und die Mentalität der Bessarabiendeutschen - hier spielte der traditionelle „Kolonistengeist“, ihr „über alle Schicksalsschläge hindurch erhalten gebliebenes Kapital“15, eine zentrale Rolle - kamen den einstigen Bauern und Handwerkern ansonsten fast überall zugute und ermöglichte es ihnen, sich in vielen Lebenslagen zurechtzufinden: als Hilfsarbeiter in der Fabrik, auf dem Bau, als Facharbeiter und als selbständige Unternehmer.

\section{Bessarabiendeutsche in der $S B Z / D D R$}

Im Unterschied zu Westdeutschland, wo die Integration der Bessarabiendeutschen mit einer fast vollständigen und abrupten beruflichen Umschichtung einherging, wurde durch die Bodenreform in der SBZ und die Ansiedlung von Vertriebenen und Flüchtlingen als Neusiedlern auch vielen Bessarabiendeutschen eine Fortsetzung ihrer bäuerlichen Existenz ermöglicht. Die bäuerliche Landwirtschaft als Produktionsform und das Dorf als Lebensform blieben für sie in der SBZ/DDR noch eine Zeitlang erhalten. Großfamilien, Nachbarschaften in den Bodenreform-Siedlungen und religiöse Gemeinschaften ermöglichten den Bessarabiern Formen des Zusammenhalts, die zumindest in

13 Immerhin waren fast $90 \%$ der Bessarabier bäuerlicher Herkunft, und auch die anderen Berufsgruppen (Handwerk, landwirtschaftliche Technik, etc.) waren im weiteren Bereich einer ländlich-agrarischen Produktion angesiedelt gewesen (Handwerker 6,6\%, Kaufleute 1,1\%, Industrielle $0,2 \%$, Intellektuelle $3,3 \%$ ).

14 Vgl. Baumann, Was wäre aus uns in Paraguay geworden? Zur Bodenreform in den Westzonen vgl. Trittel, Die Bodenreform in der britischen Zone.

15 Vgl. Erdmann, Von der Landsucht zur Landflucht, S. 129. 
den ersten Nachkriegsjahren überlebten und zum Teil noch heute bestehen. Tatsächlich haben viele Bessarabiendeutsche in der früheren DDR - trotz der verordneten sozialistischen Integrationsideologie und unterhalb der Öffentlichkeitsschwelle - ihre Gemeinschaft und ihre spezifische Mentalität viel länger und intensiver bewahrt als bisher angenommen.

Erst nach der Wende 1989 stieß ich auf das erstaunliche Phänomen, daß es in Mecklenburg, Brandenburg und Sachsen-Anhalt auch heute noch Dörfer mit einem starken Anteil bessarabiendeutscher Neusiedler gibt, in denen noch immer schwäbisch gesprochen und bessarabisch gekocht wird. Dort, wo die Bessarabier in der Mehrheit waren, hat dies sogar auf nicht wenige Mecklenburger abgefärbt. Um diesen wechselseitigen Akkulturationsprozeß genauer zu untersuchen, habe ich seit 1994 in mehreren BodenreformDörfern, in denen sich Gruppen von Bessarabiendeutschen angesiedelt haben, eine Serie von Interviews durchgeführt und ausgewertet. Die hier präsentierten Ergebnisse ${ }^{16}$ konzentrieren sich auf die interessante Konstellation in einigen mecklenburgischen Dörfern in den Kreisen Malchin und Teterow, in denen Bessarabiendeutsche - unter ihnen viele Teplitzer $^{17}$ - eine Mehrheit bei den Flüchtlingen oder sogar in der Dorfbevölkerung bildeten und dort auch die Ortsmilieus mitgeprägt haben ${ }^{18}$. Wie stark ihr Zusammenhalt noch heute ist, zeigt sich u. a. daran, daß sich bei den ersten Zusammenkünften von Bessarabiendeutschen, die nach der Wende 1989 in Mecklenburg veranstaltet wurden, mehr Teilnehmer zum lokalen Teplitzer-Treffen in Schwinkendorf einfanden als zum allgemeinen landsmannschaftlichen Treffen in Klink.

\section{Bessarabiendeutsche in mecklenburgischen Dörfern}

\subsection{Ankunft in Mecklenburg, Bodenreform, Siedlung}

Daß sich in diesen Dörfern so viele Bessarabiendeutsche niederließen, ist zum einen auf die Siedlungschancen durch die Bodenreform und zum anderen auf die Aktivierung von Verwandtschaftsbeziehungen und Nachbarschaften zurückzuführen. Hinter der „Mund-

${ }^{16}$ Dafür wurden Interviews und Gruppengespräche mit insgesamt 20 Personen aus Grambzow, Neu-Wokern, Teterow, Güstrow, Langwitz, Schwinkendorf, Waren und Hohen Pritz ausgewertet. Ihre Namen wurden in dieser Darstellung verschlüsselt.

17 Allein in cinem dieser Orte siedelten über 30 bessarabische Familien, die zumeist aus der Heimatgemeinde Teplitz stammten (vgl. Interview Frau S.). - Zu Teplitz vgl. auch unten Anm. 38 sowie Anm. 30.

${ }^{18}$ Bei diesen Gemeinden handelt es um früheren Gutsbesitz, der im Zuge der Bodenreform aufgesiedelt wurde. Die folgende Übersicht zeigt die Zahl der Neusiedler-Wirtschaften und das Verhältnis von Einheimischen und Flüchtlingen im Jahr 1946:

\begin{tabular}{|l|c|c|c|}
\hline Gemeinden & Einwohner & $\begin{array}{c}\text { Einheimische } \\
\text { Landarbeiter }\end{array}$ & Umsiedler \\
\hline Grambzow & 307 & 24 & 31 \\
Schwinkendorf & $243(1952: 364)$ & 29 & 17 \\
Langwitz & $287(1952: 286)$ & 23 & 28 \\
Christinenhof & 171 & 13 & 17 \\
\hline
\end{tabular}

Quelle: Gemeindeverzeichnis Mecklenburg-Vorpommern, 1946, S. 34-38 sowie „Die Ergebnisse der Durchführung der Bodenreform im Kreis Malchin“, MLHA, Ministerium für Land- und Forstwirtschaft, Bd. 2754. 
propaganda" steckte offensichtlich ein starkes Bedürfnis, die traditionellen sozialen Netze, die den inneren Zusammenhalt der bessarabischen Dorfgemeinschaften gesichert hatten $^{19}$ und die seit der Umsiedlung der Deutschen aus Bessarabien 1940/41 zu zerreißen drohten, wieder fester zu knüpfen. Als in der SBZ die Bodenreform in Gang kam, das Gutsland neu vermessen, aufgeteilt und noch im Herbst 1945 damit begonnen wurde, Parzellen von ca. fünf bis zehn ha ${ }^{20}$ an siedlungswillige „Neubauern“ zu verlosen, sprach sich dies unter den aus Westpreußen geflüchteten und in Mecklenburg gestrandeten Landsleuten schnell herum. Manche Familien saßen hier schon seit den letzten Kriegsmonaten fest, weil ihre Trecks und ihre Pferde zusammengebrochen waren und ihnen keine andere Wahl blieb, als sich bei den einheimischen Bauern und Gutsbesitzern für Nahrung und Unterkunft zu verdingen ${ }^{21}$. Andere waren irgendwo notdürftig untergekommen, nachdem man sie wochenlang von Dorf zu Dorf umgeleitet hatte. Frau K., die zusammen mit anderen Flüchtlingen schließlich in einem Altbauerndorf Aufnahme gefunden hatte, beschreibt ihre Situation so:

„Dann hat's geheißen, es wird gesiedelt. Und dann bin ich mal hierher gekommen und habe erfahren, daß unsere Verwandten, mein Onkel, zwei Onkel, daß die hier sind. Wo man gehört hat, daß da gesiedelt wird - wir hätten ja auch woanders siedeln können sagt meine Mutter, fahr doch hin nach Langwitz, wenn wir siedeln und ernten sollen, die Onkel können uns doch unterstützen, $[\ldots]$ und dann sind alle hierhergekommen [...] die Verwandtschaft, die wollte alle so zusammen [...] durch das sind wir alle jetzt zusammen [...] es ist so eine große Verwandtschaft." (Interview Frau K.)

Die Siedlung war, wie aus den Interviews hervorgeht, ein mehrere Jahre dauernder Prozeß. Die Initiative einzelner Männer hatte zunächst Kerne von Großfamilien um sich gezogen, denen nach und nach weitläufigere Verwandte und Bekannte - auch aus den Westzonen ${ }^{22}$ - folgten. Männer und Söhne kehrten allmählich aus der Kriegsgefangenschaft zurück und übernahmen die Wirtschaften, mit denen sich die Frauen bisher alleine abgemüht hatten. Alleinstehende Frauen oder ältere Leute, auch Berufsfremde, die die von ihnen übernommenen Siedlungen nicht mehr bewirtschaften konnten und in die Städte und Industriezonen abwanderten, gaben sie an andere Interessenten weiter. Auf diese Weise bildete sich für die Bessarabier in den ersten Nachkriegsjahren in einer völlig fremden Umgebung so etwas wie eine neue Heimat heraus, die nach den Wirren der Umsiedlung und Flucht von Dauer zu sein schien, und in deren Lebensformen und Sozialbeziehungen sich Züge des früheren Gemeinschaftslebens erhielten oder wieder einstellten.

${ }^{19}$ Dies gilt in besonderem Maße für die im Zuge der ersten Auswanderungswelle (1814-1824) gegründeten "Mutterkolonien“.

20 Die bessarabischen Bauern hatten im Schnitt wesentlich größere Höfe besessen. (Zu einer "Wirtschaft" gehörten in Bessarabien ursprünglich 60 Deßjatinen, i. e. ca. 66 ha, was allerdings aufgrund von Erbteilungen später nicht mehr der Normalfall war. Die Bauern in den aus der rumänischen Bodenreform nach dem Ersten Weltkrieg hervorgegangenen „Hektardörfern“ waren mit ihren fünf ha großen Höfen kaum überlebensfähig.) - Für einige Flüchtlinge war der Statusverlust immens: Einer der „Neusiedler" aus Teplitz hatte z. B. mit seiner Doppelwirtschaft in Bessarabien mehr Land bearbeitet als mancher mecklenburgische Gutsbesitzer. Vgl. Interview Herr O.

21 In Grambzow waren das etwa zehn Familien. Vgl. Interview Frau S.

22 So hatte z. B. Herr A. bereits eine gute Stellung bei einem Bauern in Schleswig-Holstein gefunden; Herr G. war durch einen Kriegskameraden auf eine Zeche im Ruhrgebiet vermittelt worden, wollte aber nicht „804 m unter der Erde“, sondern lieber wieder „freier Bauer auf freier Scholle“ sein. 
Konstitutiv dafür waren: die bäuerliche Arbeit auf dem eigenen Hof, die auf familialer Kooperation basierte und immer wieder auch Nachbarschaftshilfe erforderte, der vertraute schwäbische Dialekt als Ausdrucks- und Kommunikationsform sowie ein kirchlich-protestantisch geprägtes Wertsystem.

\section{2. „Angesehen waren wir Flüchtlinge nicht....“}

Das Verhältnis zwischen Einheimischen und Zuwanderern war in der Anfangsphase offenbar äußerst gespannt. Die Flüchtlinge seien - so Frau H. - „nicht erwünscht" gewesen, sondern „als Eindringlinge betrachtet" worden und hätten sich „schwer durchbeißen müssen“. Gelegentlich findet sich in den Interviews eine Tendenz zur nachträglichen Harmonisierung: Wie überall, so habe es auch hier rücksichtslose wie gutherzige Menschen gegeben. Ganz zu Anfang sei es freilich "oft schlimm“ gewesen, dann aber hätten die Mecklenburger erkannt, daß die Bessarabier fleißige und ordentliche Menschen gewesen seien. Der versöhnliche Blick auf die schwierige Nachkriegsphase erklärt sich vermutlich auch daher, daß es zahlreiche "Mischehen“ mit Mecklenburgern gab und daß sich die einheimischen Ehepartner mit ihrem familiären Anhang oft recht gut in die bessarabische Mehrheitskultur eingelebt hatten ${ }^{23}$.

Aufschlußreich sind die Interviews mit den Angehörigen der zweiten Generation, die die Diskriminierung der Flüchtlinge, die sie als Kinder bzw. Jugendliche erfuhren, noch nicht vergessen haben und drastische Beispiele dafür benennen. Demnach gab es in der ersten Nachkriegszeit, auch noch in den Anfängen der Bodenreform, massive Verteilungskonflikte zwischen Alteingesessenen und Flüchtlingen. Sie schwächten sich in dem Maße ab, wie es den Zuwanderern gelang, sich hochzuarbeiten, bis sich schließlich sogar eine Art Neid auf deren bescheidenen Wohlstand einstellte. Länger hielten sich Aversionen, die sich an kulturellen und habituellen Differenzen wie dem schwäbischen Dialekt, der ungewohnten Sprechweise und Tonlage der bessarabischen Frauen ${ }^{24}$, dem aktivistischeren Temperament der Bessarabier ${ }^{25}$, ihrer puritanischen Arbeitsmoral und ihrem Erwerbsstreben festmachten; vereinzelt geben sie noch heute Stoff für Vorurteile und Sticheleien her ${ }^{26}$.

Frau S., die als 15 jährige noch vor Kriegsende mit ihrer Familie in Grambzow auf dem Gut eingewiesen wurde, weil sie mit ihrer gebrechlichen Familie und ihren erschöpften Pferden nicht mehr weiterkam, beschreibt, daß die Ankömmlinge vom Gutsverwalter nicht nur unbarmherzig behandelt, sondern auch noch ausgenützt wurden:

„Unsere Pferde, die ja nun vier Wochen - die wurden am zweiten Tag wieder vor'n Pflug bei ihm gespannt, und seine hat er im Stall stehen lassen. [...] Wenn er sie hätt' wenigstens acht Tage ausruhen lassen, er hatte ja genug Pferde und Trecker, nein - das waren ja die von den Flüchtlingen." (Interview Frau S.)

${ }^{23}$ Solche ungewöhnlichen Akkulturationsprozesse wurden von manchen Interviewpartnern auch als Zeichen einer gelungenen Integration betrachtet.

${ }^{24}$ Die bessarabischen Frauen seien am Anfang wegen ihres Dialekts und ihres Aussehens geradezu "verhöhnt“ worden. „Sie hatten es nicht einfach, die erste Zeit. Sie hatten es sehr schwer da. Ja, bloß wie die [Mecklenburger] sich dann daran gewöhnt hatten, es kamen ja noch mehr Flüchtlinge, dann ging das dann nachher, da hat sich das eingegliedert." (Interview Herr K.)

${ }^{25}$ So charakterisierte es ein Interviewpartner der zweiten Generation: „Bessarabier, die sind - die können eben nicht stillsitzen, das kann man bei keinem sehen, die sind eben nur im Trab, und die Gosche steht nie still." (Interview Herr K.)

${ }^{26}$ Interview Herr U. 
Noch heute empört sich Frau H. darüber, daß der Gutsbesitzer bzw. sein „Statthalter“ - sozusagen als Gegenleistung für die Unterbringung der Ankömmlinge - ganz selbstverständlich deren Pferde übernahm und sie ausschließlich für sich arbeiten ließ ${ }^{27}$. Solche Erfahrungen trugen sicherlich mit dazu bei, daß der Gutsherr, als er im Zuge der Bodenreform sein Gut verlassen mußte, nicht mit der Sympathie der Flüchtlinge rechnen konnte.

In der Zwischenphase bis zur Aufsiedelung kam es freilich auch zu Zusammenstößen mit der Dorfbevölkerung, die ihre vermeintlichen Vorrechte gegenüber den Flüchtlingen strikt verteidigte - wenn es z. B. darum ging, sich die Hinterlassenschaften im Gutshaus anzueignen oder die Nahrungsmittelbestände eines aufgegebenen Wehrmachtsdepots zu verteilen. Allmählich konnten die Flüchtlinge aber, aufgrund ihrer zahlenmäßigen Überlegenheit und der zunehmenden Bereitschaft, sich zu wehren, ihre Ansprüche auf Gleichbehandlung und Gleichberechtigung durchsetzen:

„Wir haben uns nachher behauptet, die Flüchtlinge, weil wir mebr waren, und die haben auch gesehen, was wir konnten, sozusagen, also sie waren nachher - zugänglicher zu uns." (Interview Frau S.)

„Die haben mehr für sich gesorgt, wollten uns nichts geben, ne, oder wenig zukommen lassen, aber wir haben uns das nicht gefallen lassen, ne, [...] wenn ibr nehmt, können wir auch nehmen! Die haben ja ihre Kuh gehabt, ihre eigene, und so, wir haben ja nichts gehabt." (Interview Herr O.)

Doch auch bei der Bodenreform hatten die Flüchtlinge Grund, sich benachteiligt zu fühlen: Die vorhandenen Häuser wurden unter den Einheimischen verlost, die Flüchtlinge erhielten hingegen nur Bauplätze. In Massenquartieren, früheren Zwangsarbeiter-Baracken, Lehmhütten und Bretterbuden untergebracht, mußten sie sich erst Baugenehmigungen und Baumaterial besorgen, um Haus, Scheunen, Ställe zu bauen. Als ungerecht empfanden die Flüchtlinge auch, daß die Eingesessenen bei der Verteilung der Viehbestände der Gutsherren nur ihren eigenen Vorteil im Auge hatten, obwohl sie im Unterschied zu ihnen noch über eigene Ressourcen verfügten ${ }^{28}$. So war es in Grambzow vor allem der Initiative des russischen Kommandeurs zu verdanken, daß die Flüchtlingsfamilien ausreichend mit Milch versorgt wurden ${ }^{29}$. Weil die Zuwanderer meistens keine Zugkraft, keine Maschinen, kaum Gerät besaßen, mußten sie in den ersten Jahren z. T. bei den Einheimischen mitarbeiten, um deren Pferde wenigstens zeitweise zum Pflügen ausleihen zu können ${ }^{30}$.

${ }^{27}$ Hingegen mußten die Flüchtlinge z. B. das Feuerholz, das sie brauchten, um Rüben zu Sirup zu verarbeiten, im Wald schlagen und mühsam in ihre Unterkünfte schleppen. Vgl. Interview Frau H.

${ }^{28}$ Frau H. und zwei weitere Siedlerfamilien teilten sich z. B. eine Kuh, während die einheimischen Familien jeweils mindestens eine Kuh hatten (ähnlich auch Herr O.). - Derartige Aussagen werden durch die Berichte der Bodenreformkommissionen sowohl für die hier untersuchten als auch für andere Orte bestätigt. Besonders auffällig ist die ungleiche Verteilung der Pferde. In den Bodenreformkommissionen waren die Umsiedler übrigens nur unzureichend oder gar nicht vertreten. Vgl. MLHA, Ministerium für Land- und Forstwirtschaft, Bd. 2754.

${ }^{29}$ Vgl. Interview Frau S. - Zur Ernährungssituation vgl. auch Frau L. aus Hohen Pritz: „Und die Mecklenburger haben die Flüchtlinge auch nicht akzeptiert, dann sind wir gegangen und haben um die Milch gebettelt, sozusagen, die Einheimischen, die hatten ne Kuh, und die hatten Getreide, wir hatten nischt zu essen. Und Pferdeschrot, das war wie so Sägespäne, da haben wir Brot, wie so ne Fladen, gebacken. Einfach so auf der Herdplatte, ham wir die gebacken, dann zum Mittag hat's Kartoffel und Sirup gegeben, gestippt.“

${ }^{30}$ Interview Frau S. - Der Mangel an Pferden war auch eine Folge der Requirationen durch russische Soldaten. 
Aus Fohlen zogen sie sich dann eigene Pferde heran, so daß sie mit anderen Bauern zusammenspannen und unabhängiger wirtschaften konnten. Die ersten Ernten wurden zumeist noch mit der Sense abgemäht.

\subsection{Die Mühsal der Einzelbauern}

Bis zum Beginn der fünfziger Jahre ist der Aufbau der Einzelwirtschaften ein hartes Stück Arbeit gewesen. Mühsam wurden nach und nach eigene Viehbestände aufgebaut, landwirtschaftliches Gerät angeschafft, die Felder in Ordnung gebracht und bestellt. Herr A., der als 20jähriger erst im Januar 1948 nach Kriegsgefangenenschaft und zeitweiliger Beschäftigung als Knecht auf einem holsteinischen Bauernhof nach Mecklenburg kam, weil seine Eltern dort mit ihm zusammen siedeln wollten, beschreibt - hier exemplarisch für andere Interviewpartner, die von ähnliche Anstrengungen berichteten - die Mühen der Anfangszeit, aus denen es diese Familie später zu einer ansehnlichen Pferdezucht brachte:

„Ich war vordem in Schleswig-Holstein - beim Bauern, aber mein Vater war nun hier, und der Onkel war hier, und es war hier nun eben damals durch die Bodenreform möglich, Land zu bekommen. Und, ich hatte nun eben sehr große Lust zur Landwirtschaft, und um da [im Westen] nun Land zu bekommen, das war unmöglich. [...] Was da war zum Verkauf, da kamen erst mal die Einheimischen und - kein Flüchtling. - Ja, und dann hier - angefangen, und - eben praktisch fast mit nichts angefangen, - wir haben zuerst, als wir nun - Kartoffeln gepflanzt und - gehäufelt haben, wir hatten keine Zugkraft, da haben wir dann, der Onkel, Vater und ich, einer hat den Pflug gehalten, und zwei Mann haben gezogen. Selber als Zugkraft haben wir's erst mal in Gang gehalten und haben dann über die Bodenreform Ochsen bekommen, und dann nochmal 'n Ochsen dazu - und dann 'n Kalb, und das Kalb wurde dann zur Kuh, und so hast du allmäblich aufgebaut [...] und dann die Kuh noch mit angespannt zu den Ochsen. Und da hat man, da wir ja nun Württemberger sind, hat man uns nachgesagt - die Mecklenburger - naja, die Schwaben können ja mit Ochsen und Kühen fahren, wir können das nicht. Bloß, wir haben ja in Bessarabien auch keine Kuh und keinen Ochsen angespannt, da kannten wir überhaupt nischt von, nich, da sagten wir immer, wenn ihr wüßtet, was wir für Pferde hatten! So, und wir waren am Anfang gar nicht so sehr scharf auf Pferde, denn - man mußte hier sehr viel Langholz fahren damals, [. . . ] wir konnten mit den Ochsen und Kühen eben unsere Arbeit machen und wurden da nicht gestört, nich. Man mußte zwar, was das Kuriose dabei war, für jeden Ochsen im Jahr auch noch mal 36 Kilo Fleisch liefern, wie sie sich das gedacht haben, weiß man nicht, ob man da jedes Jahr 'n Schinken rausschneiden sollte, vom lebendigen Ochsen? [...] Naja, dann haben wir irgendwie 'n Rind, 'n anderes Rind, aufgezogen, und das wurde dann eben dafür abgeliefert. Brot und Getreide war ja auch ganz knapp, da hat man dann eben bißchen Getreide sich irgendwie organisiert, und das haben wir dann ganz fein geschrotet, das haben die Frauen ganz fein durchgesiebt, und da wurde dann Brot von gebacken - viel Sirup, Pellkartoffeln in Sirup gegessen. - Und als es dann soweit war, wie wir dann auch schon mal zu Schweinen kamen und uns ein Schwein aufgezogen hatten - um zu schlachten, da haben wir dann gesagt, jetzt ist es langsam an der Zeit, daß wir zu Pferden kommen. Und da haben wir uns, anstatt das Schwein zu schlachten, haben wir das mit den Altbauern - es waren ja hier ansässige Bauern, die waren ja doch, die saßen fester im Sattel als wir, die Neubauern - und haben uns dann eben für das Schwein ein Fohlen eingetauscht und [wir haben] 
da noch Getreide zugegeben, da wir ja nun die Ochsen hatten. Ochsen brauchen ja nicht ganz so viel Getreide wie Pferde - da konnten wir das eben einsparen. [. . . Hat man uns wieder ausgelacht. Die Mecklenburger sagten dann wieder zu uns, was wollt ihr mit'm Fohlen, wir müssen Pferde haben - auch ein Fohlen wird ein Pferd, nich? Ja, und dann das Jahr drauf nochmal ein Fohlen eingetauscht. So sind wir dann angefangen, die Kühe dann stehenzulassen, um nur noch Milch zu geben und haben dann die Fohlen vorne bei den Ochsen angespannt, haben wieder mit vieren gefahren. Und allmählich dann die Ochsen nachher mal späterhin vertauscht, wieder für Fohlen, so daß wir dann mit ner Weile vier Pferde beieinander hatten. Und dann haben wir nachher eben auch angefangen zu züchten und konnten dann unsere Pferde uns selbst heranzüchten, beziehungsweise eben dann schon mal wieder was verkaufen. Und wir sind ja auch eben diejenigen, die hier dann [...] die Pferdezucht aufgebaut haben." (Interview Herr A.)

Filtert man aus den Interviews die Faktoren heraus, die die „Karrieren“ der bessarabischen Einzelbauern in Mecklenburg gefördert haben, so verdichten sie sich in fünf Punkten: Sie enthalten Merkmale und Identifikationsmuster, die sich auf Herkunft und Siedlungsgeschichte, spezifische Wanderungsbedingungen und kulturelle Deutungsmuster der Bessarabiendeutschen beziehen, und die sie z. T. von ihren einheimischen Nachbarn, aber auch von Flüchtlingsgruppen aus anderen Herkunftsgebieten unterschieden.

\section{a) Integrationsbereitschaft}

Aufgrund ihrer Umsiedlungs- und Fluchtgeschichte machten sie sich (im Unterschied zu anderen Flüchtlingen aus den Gebieten jenseits der Oder-Neiße-Linie oder aus dem Sudetenland) keinerlei Illusionen über eine mögliche Rückkehr in ihre alte Heimat. Daher betrachteten sie ihre gegenwärtige Lage nicht als Provisorium, sondern setzten alles daran, unter den gegebenen Bedingungen möglichst bald wieder seßhaft zu werden.

\section{b) Qualifikation}

Im Unterschied zu den mecklenburgischen Gutsarbeitern waren die bessarabischen Neusiedler in ihrer Heimat selbständige Bauern gewesen und wollten dies auch nach 1945 wieder $\operatorname{sein}^{31}$. Nicht wenige von ihnen brachten zudem handwerkliches Geschick mit, besonders diejenigen, die sich - wie viele der Teplitzer - nicht nur in der Landwirtschaft auskannten, sondern auch etwas vom Wagner-, Schlosser- oder Schmiedeberuf verstan$\operatorname{den}^{32}$. In den mecklenburgischen „Bessarabier-Dörfern“ konnten überdies die in der Kolonistenzeit in Bessarabien über Generationen eingeübten und praktizierten gemeinschaftlichen Kooperationsformen z. T. wieder reaktiviert und als „soziales Kapital“ genutzt werden, das manchen Nachteil ausglich.

${ }^{31}$ Das Interesse der Flüchtlinge an der Aufsiedelung war daher z. T. noch deutlicher ausgeprägt als bei den Gutsarbeitern. Vgl. Interview Herr A.

32 Gerade den Teplitzern wurden auch Eigenschaften wie „eine Geschicklichkeit und Handfertigkeit auf allen Gebieten des praktischen Lebens“ sowie kommerzielles Geschick und „Zungenfertigkeit " ${ }^{\prime}$ attestiert. Vgl. Weiß, Geschichte der Kolonie Teplitz, S. 153. - Das bessarabische Dorf Teplitz hatte sich in der zweiten Hälfte des 19. Jahrhunderts zu einem Zentrum des Wagenhandwerks entwickelt. Bis zum Ersten Weltkrieg erschloß es sich Absatzmärkte auch außerhalb Bessarabiens in Südrußland und im Kaukasus und belieferte auch die russische Armee. Nachdem dieser Marktzugang 1918 abgeschnitten wurde, begann sich in Teplitz eine landwirtschaftsnahe Industrie zu entwickeln. 


\section{c) Erfahrungen nach der Umsiedlung}

Bereits während der Ansiedlungszeit in „Westpreußen“ hatten sich die bessarabiendeutschen Bauern auf klimatische Verhältnisse, Methoden der Bodenbearbeitung, Vegetationszeiten umstellen müssen, die sich von den Bedingungen in ihrer alten Heimat stark unterschieden ${ }^{33}$. Die neuerworbenen Erfahrungen, Kenntnisse und Praktiken ließen sich auch für die Arbeitsweise in Mecklenburg nutzen und halfen ihnen, die Schwierigkeiten der Anfangsjahre zu meistern.

\section{d) Arbeitsmoral}

Die Einstellung zur Arbeit, die sich in der Siedlungsgeschichte der Bessarabiendeutschen ausgeprägt hatte, war auch in der Nachkriegszeit ungebrochen. Nach dem doppelten Heimatverlust kam dem Sediment einer säkularisierten pietistischen Ethik als einer zentralen identitätsstiftenden Komponente vermutlich eine noch höhere Bedeutung zu. Diese Arbeitsmoral prägte vor allem den Alltag der Einzelbauern, wurde aber auch noch in der LPG-Zeit beibehalten. Sie äußerte sich im Zeitaufwand, in der Intensität und der Identifikation mit der Arbeit:

„Die Bessaraber han g'arbeitet, bis d'Sonn unterging und sind um fünfe uff'gstande. Des hat sich nachher bewiese." (Interview Frau E.)

"[Es ist ihnen später ganz gut gegangen], aber, wer weiß, wie lang die gearbeitet haben - solange es hell war!" (Interview Frau K.)

„Und auch im Arbeiten sind die viel zu schnell, und das ist ja gerade auch dieser Arbeitsstil. Wenn die [Mecklenburger] wissen, sie müssen mit nem Bessaraber zusammenarbeiten - in der ersten Zeit haben sich viele geweigert, mit einem Bessaraber zusammenzuarbeiten hier in Mecklenburg, auf dem Land, in der LPG zum Beispiel, weil sie genau wußten, sie müßten sich an dieses Tempo gewöhnen, und das haben viele nicht gemacht." (Interview Herr K.)

„Die Bessaraber haben immer ne eigene Clique geführt, wenn sie jetzt so ne Arbeitsteilung hatten, waren immer Bessaraber zusammen. Selten mit Mecklenburgern, weil sie genau wußten (oder Verwandte oder Verschwägerte, wo sie eingeheiratet haben) - allgemein: die Bessaraber waren aktiver, wesentlich aktiver, sie waren - der Motor, praktisch.“ (Herr K./Herr U.)

\section{e) Selbstbilder und Deutungsmuster}

Dazu gehörten der sprichwörtliche Pioniergeist ${ }^{34}$, eine ausgeprägte Leistungsorientierung sowie Durchhaltevermögen. Charakteristisch für die Bessarabier in Ost- wie Westdeutschland war das Bestreben, sich aufgrund eigener Leistung behaupten zu können, niemandem zur Last fallen zu müssen, die Kinder zu tüchtigen und selbstverantwortli-

${ }^{33}$ Vgl. Becker, Wie's daheim war, S. $144 \mathrm{f}$. - So erforderte z. B. die bessarabische Schwarzerde keinerlei Düngung. In Bessarabien wurde mehr Weizen als Roggen, kaum Kartoffeln, keine Zuckerrüben, aber viel Mais, Gerste und Hafer sowie Wein angebaut. Auch die Tierzucht und -fütterung unterschied sich: Es wurden mehr Pferde und Schafe, weniger Kühe und Schweine gezüchtet.

${ }^{34}$ Das bessarabische Sprichwort „Den ersten der Tod, den zweiten die Not, den dritten das Brot" brachte die Erfahrungen der Auswanderergenerationen auf den Punkt. - In Zeiten zunehmender Landknappheit dorthin zu wandern, wo man siedeln konnte, war übrigens auch eine in Bessarabien übliche Praxis. 
chen Menschen zu erziehen. Die Identifikation mit dem, was sie und ihre Vorfahren in nur fünf Generationen geschaffen (und zweimal verloren) hatten, bildeten den Ansporn und die Zuversicht, ein weiteres Mal von vorn beginnen zu können.

\section{4. „Sozialistischer Frühling“}

Ende der fünfziger Jahre setzte in den mecklenburgischen Dörfern die „große Umgestaltung $^{\text {“ } 35}$, d. h. die Kollektivierung der Landwirtschaft, ein. Die 1952 mit einem Beschluß der SED eingeleitete Kampagne zur Bildung von landwirtschaftlichen Produktionsgenossenschaften (LPG) wurde nach dem 17. Juni 1953 zeitweise ausgesetzt, dann aber Ende der fünfziger Jahre wieder forciert. Schon vorher gab es die ÖLB („Öffentliche Landwirtschaftsbetriebe“), in denen brachliegende bzw. von Einzelbauern aufgegebene Flächen bewirtschaftet wurden. Die Vorwehen des - von einigen Interviewpartnern auch als „Umsturz" bezeichneten - Umbruchs waren freilich schon lange zu spüren. So war es für Herrn O., der zu den ersten „Neusiedlern“ in Grambzow gehörte, eine der herbsten Enttäuschungen seines Lebens, daß er den von ihm geplanten Hofneubau nicht ausführen konnte, weil er dafür kein Baumaterial mehr erhielt ${ }^{36}$.

Eine Übergangsform zwischen den „ÖLB“ und der LPG „Typ 3“ stellte die LPG „Typ 1“ dar, die den Bauern noch eine gewisse Selbständigkeit und Eigenverantwortung gestattete: Hier wurden nur die Ackerflächen kollektiviert, die Tierhaltung betrieben die Bauern nach wie vor privat. Die Familienbetriebe konnten also zunächst noch aufrechterhalten werden und mehrere Einzelbauern (in Gruppen von ca. fünf bis zehn) zusammen wirtschaften. Mit dieser Übergangsregelung gelang es der Staatsführung, die Widerstandspotentiale in der Neubauernschaft vorübergehend zu pazifizieren und zugleich Engpässe in der Versorgung der DDR-Bevölkerung mit Lebensmitteln zu begrenzen.

Manche bessarabischen Familien gelangten in den sechziger Jahren zu einem bescheidenen Wohlstand, für den allerdings von früh bis spät fast ununterbrochen gearbeitet werden mußte.

„Sieben Jahre waren wir in Typ 1 - noch fünf Einzelbauern. Wir haben uns dann auch zusammengeschlossen. Wir mußten ja auch abliefern, aber das, was wir uns aufgezogen haben, das war unser eigenes. Und da haben wir uns ja dann hochgearbeitet. Wir haben Bullen abgeliefert, Bullen gefüttert, die haben doch viel Geld gebracht. Mit Schweinen war's genauso und Kühen. Und da haben wir uns hochgeschafft und konnten uns ein bißchen behelfen und was anschaffen." (Interview Frau K.)

Noch vor der Feldarbeit wurde bei Tagesanbruch das Vieh gefüttert, abends wurde gemolken und wieder gefüttert. Auch die Kinder hatten ihre festen Pflichten und riskierten harte Strafen, wenn sie sie nicht einhielten:

${ }^{35}$ Interview Herr F.

${ }^{36}$ Die großen Stallungen und Kornspeicher der Güter waren zunächst teilweise stehengeblieben und von den einzelnen Bauern auch gemeinsam genutzt worden. Sie wurden dann aber - aus primär ideologischen Gründen - oft abgerissen, weil der "gutsherrliche Charakter“ der Dörfer beseitigt werden sollte; das Baumaterial verwendeten die "Neubauern“ zum Aufbau ihrer Häuser, Scheunen und Ställe. Zur Einführung der Großraumwirtschaft waren später wieder große Anlagen erforderlich, die zumeist an den Dorfrändern neu erbaut wurden. Mit Blick auf die künftige Umstrukturierung der Dörfer hielt man nun die Einzelbauern davon ab, neue Wirtschaftsgebäude zu errichten; die Neubauten wurden schon auf das "Prinzip LPG“ hin orientiert. Vgl. auch Interview Frau S., Herr R., Herr A. 
„Bei uns war es schon einfacher - bei meinen [älteren] Schwestern, also bei den Einzelwirtschaften, war es schlimm - aber wir mußten jeden Tag, mein Vater ist auf's Feld gefahren, U. und ich mußten auf den Pferdewagen, und dann hat er gemäht, und wir mußten das Futter zusammenrechen und aufladen. Und dann mußten wir nach Haus, wurd's abgeladen. Und eine Aktion, die jeden Tag war: Kühe holen. Jeden Tag mußten wir die Kühe holen. Weil die Eltern auf dem Feld waren, und wehe - einmal waren die Kühe nicht zuhause!!! [...] - Und das hatten wir auch gesehen, die Kinder von den Eltern, die auf Typ 3 waren, die konnten nachmittags baden fahren, konnten spielen, wir mußten, wir haben unsere Pflichtaufgaben gehabt, und das war eben - für die Kinder war es auch keine schöne Zeit. Deswegen wurden wir so ein bißchen ausgegrenzt. Oder vielmehr: die Kinder von Typ 1, paar hielten zusammen, und paar Kinder von Typ 3 hielten zusammen. Aber dadurch, daß wir Verwandtschaft hatten, war es nicht ganz so extrem.“ (Interview Herr K.)

Die strenge Einbindung der Kinder in den Arbeitsalltag der Eltern beförderte - wie hier angedeutet - mancherorts eine Gruppenbildung unter den Jugendlichen, die allerdings durch Verwandtschaft und Nachbarschaft wieder gemildert wurde. Das soziale Gefälle zwischen „1 er“- und „3 er“-Kindern kehrte sich in den sechziger Jahren um, als die Wirtschaften des „Typ 1 “ zu florieren begannen und sich das in einem stärkeren Selbstbewußtsein und deutlich besseren Konsumchancen der „1 er“-Kinder niederschlug. Die Selbstausbeutung der Einzelbauern und ihrer Familienangehörigen, gerade auch der Kinder, war andererseits aber auch mit ein Grund dafür, daß manche, vor allem jüngere Leute, oft auch Frauen, nicht erst den Umweg in "Typ 1“ machen wollten, sondern sich gleich für den Eintritt in „Typ 3 “ entschieden.

In den sechziger Jahren wurden die LPGs „Typ 1“ aufgelöst und allmählich in „Typ 3“ überführt. Viele Bessarabiendeutsche gehörten offensichtlich mit zu denen, die sich am längsten gegen die Kollektivierung gesträubt hatten. Bis heute empfinden sie es als ungerecht, daß diejenigen, die frühzeitig in die ÖLB und die ersten LPGs eintraten, weil sie nicht hätten wirtschaften können oder „es alleine nicht mehr geschafft haben“, vom Staat mit großzügigen finanziellen Anreizen, mit Einkommenssicherung und moderner Landtechnik „belohnt“" worden seien, während sie selbst und andere - gezwungen durch den politischen Druck, die Abgabenlasten, mangelnde Ausstattung und Maschinen - die von ihnen geschaffenen Werte schließlich zum Schleuderpreis in die LPGs einbringen und sich dort sogar noch mit vergleichsweise hohen Summen einkaufen mußten ${ }^{37}$.

Wie haben die Bessarabier diesen Bruch, die Aufgabe ihrer schwer erarbeiteten selbständigen Existenz, verkraftet? Die Interviews zeigen ein Spektrum von Reaktionsformen. Vor allem für die Älteren bedeutete die Kollektivierung eine neuerlichen, kaum verschmerzbaren Verlust, Enttäuschung und Resignation. Jüngere Leute, oft auch Frauen, zogen sich nicht selten auf einen „realistischen“ Standpunkt zurück: Mangels anderer Alternativen fanden sie sich mit den unvermeidlichen Veränderungen ab, zumal die Großraumwirtschaft zeitweise durchaus eine gewisse Rationalität für sich beanspruchte und die LPGs in ihren Dörfern - nicht zuletzt durch ihre eigene Mitarbeit - recht gute Ergebnisse vorweisen konnten. Es gibt auch Befragte, denen in der LPG eine ebenso gute, vielleicht sogar eine befriedigendere Verbindung von Erwerbsarbeit, Hobbys und Interessen gelang, als ihnen dies unter anderen Voraussetzungen möglich gewesen wäre - ins-

37 Als die LPG entstand, mußten pro ha 350 Mark Einstand gezahlt werden; 1968 waren es bereits 850 DM (vgl. Interview Frau K.). 
besondere dann, wenn ihre speziellen Fähigkeiten aufgegriffen und für die LPG genutzt wurden. Einige Beispiele dafür aus den Interviews:

Die Bessarabier aus Hohen Pritz berichteten, der Beitritt zur LPG sei ihnen allen sehr schwer gefallen; der Druck sei aber zu stark geworden.

„Die haben die Leute direkt überfallen, die sind von Haus zu Haus, und wehe, Sie haben gesagt: nee!" (Frau T.)

"Die sind von oben, von Sternberg und von Schwerin her gekommen." (Herr V.)

Frau E. erzählt, sie selbst habe in der akuten Phase die Männer ihrer Familie davon abgehalten, sich offen gegen die Kollektivierung aufzulehnen. Denn gerade die Bessarabiendeutschen seien durch die Vorgänge nach dem Einmarsch der Roten Armee in Bessarabien am 28. Juni 1940, bei denen zwar nicht die Deutschen, aber unbotmäßige Angehörige anderer Nationalitäten von den Russen drangsaliert worden seien, gewarnt gewesen:

„Zletscht hot mr ja Angscht g'het. Die waret hier, der Andreas und der Richard und der Albert, die drei [...], die hen sich uffg'regt wege alles, und da han i g'sagt, wie se erzählt hen, seid mal ganz still, muckset euch mal [net], hen ihr net g'hört von Rußland, die holet euch abends weg, ihr sehr kein Licht mehr, no hen se nachgä. Da waret Spitzel bei und alles, wo g'horcht hen, was der und der sagt." (Interview Frau E.)

Für Frau E. bedeutete der Wechsel in die LPG freilich einen sozialen Abstieg, an dem letztlich auch ihr Mann seelisch zerbrochen sei. Ihre Rettung sei nur gewesen,

„daß sie uns a bißle Acker g'lasse hen und Kuh, Schwein, bißle Geflügel, und des hen mr nach Feierabend g'macht, das war unser Leben, sonst hätte das Geld net gereicht, was mr nach Haus bracht' hen: 300 Mark - und sieben Kinder!!" (Interview Frau E.)

Die Familie von Frau K. in Langwitz gehörte mit zu den letzten, die im Jahr 1968 aufgaben und von der LPG „Freiheit“ (Typ 1) zur LPG „Neues Dorf“ (Typ 3) wechselten. Nach all den Jahren, in denen sie sich "hochgearbeitet" und „etwas gehabt hatten“, mußte sie nun wieder von vorn beginnen: ein 9-Stunden-Tag auf dem Feld, Arbeit in drei Schichten, auch samstags und manchmal sonntags, ein kleiner Verdienst, der für sie und ihre drei Kinder kaum reichte. Ihr Mann war damals schon Invalidenrentner, bis er drei Jahre später starb. Auch für die Kinder war es ein Einschnitt,

"wie es auf dem Hof plötzlich so still wurde, als die Pferde weg waren, was hatten wir für schöne Pferde, es waren auch Reitpferde, bei Turnieren [...] für uns Kinder war's schlimm, wie - weil die Pferde vom Hof gingen. Jeder hat zwar noch eine Kuh gehabt, ein paar Schweine und Bullen durften sie noch halten, aber das große Viehgeschäft war weg." (Interview Herr K.)

Herr K. erzählt, die älteren Männer (wie sein Vater) hätten die Kollektivierung nicht mehr verkraftet:

„Für die Alten war 's ein ganz schlimmer Umbruch, die Jüngeren haben das gelassener hingenommen. [...] Erst mal diese ganze Umsiedlung, die ganze Flucht und dann auf einmal diese neue Umstellung - erst bißchen Land gehabt und dann auf einmal mußten sie das Land wieder abgeben - und ich nehme an, daß denn - viele nicht mehr die Kraft hatten [...] viele haben das Rentenalter gar nicht mehr erreicht [...], das waren alles Wracks! Die alten Leute waren am Ende kaputt, und die sind auch alle nicht alt geworden. Die haben grade mal die 70 erreicht." (Interview Herr K.)

Andere, Jüngere, die noch auf der LPG tätig gewesen seien, hätten sich aber hier auch weiterhin stark eingesetzt und mit der LPG in ihrem Ort identifiziert:

„Also, sie haben sich nicht gehen lassen - wie sie in der LPG waren, sie hätten sich ja verhalten können wie die Altbauern in den reichen Dörfern - hätten sagen können, was 
interessiert mich die LPG. Die in unserem Dorf haben gesagt: Wir sind nun mal hier, wir arbeiten hier, und wir machen auch was! Und die haben sich auch voll eingesetzt dafür. Und die Leitungen, die dort die LPG geführt haben, die wußten auch, daß sie sich auf die Leute verlassen konnten." (Interview Herr K.)

Herr B., der drei Jahre lang als Bereichsleiter in der Rinder- und Milchproduktion der Schwinkendorfer LPG tätig war, ist der Meinung, daß die LPG ihren guten Stand nicht zuletzt den Bessarabiern mit zu verdanken gehabt habe:

„Der gestandene Mecklenburger hat immer gesagt, die Bessaraber sind verrückt. Die haben - selbst nachher, wie's ja von der Einzelbauerwirtschaft rüberging in die LPG Typ 3, wo sie's ja nicht mehr nötig hatten, wo [. . . ja - [...] Stundenlohn bezahlt wurde - ihren Acht- oder Neun-Stundentag [gehabt], die Arbeitszeit war um 17 Uhr vorbei die waren um 19 und $20 \mathrm{Uhr}$ noch in den Stallungen und haben nach dem Vieh gekuckt. [... . Die haben nicht gearbeitet, daß die viel Geld verdienen, die haben gearbeitet, daß es den Tieren gut geht, daß der Ort nach außen hin ein Ansehen erlangt. Das war für die viel wichtiger." (Interview Herr B.)

Schwer war die Umstellung für die selbstbewußten und erfolgreichen Bauern, die wie Herr O. - keine Probleme gehabt hatten, ihr Soll abzuliefern. Er wurde heftig umworben, der Genossenschaft beizutreten, wehrte sich jedoch lange („ich hab's ja gewußt, was kommt: die Kolchose!") und lehnte auch das Angebot, LPG-Vorsitzender zu werden ab, denn:

„Wir waren ja Selbständigkeit gewohnt, ne, [.. . ] so mußten wir uns also einfinden, die erste Zeit war schwer." (Interview Herr O.)

Auch Herr A. erzählt, er sei sechs Jahre lang umworben worden. Als er schließlich 1966 aufgab, brachte er zusammen mit seinem Vater und Onkel sieben Zuchtstuten in die Genossenschaft ein. Er arbeitete zunächst im Stall als Futtermeister und wurde dann Leiter der Abteilung Pferdesport und -zucht, die nicht wenig zum Renommee der insgesamt sehr erfolgreichen LPG „Neues Leben“ beitrug. Als Leistungssportler ging Herr A. auch in den "großen Sport" und gewann viermal den DDR-Meistertitel im VierspännerFahren. Der Umgang mit Pferden hatte in dieser Familie Tradition; bereits der Großvater hatte in Bessarabien die begehrten Orloff-Traber besessen, der Vater fütterte Pferde auf und verkaufte sie an rumänische Offiziere, auch Herr A. mußte von Jugend an mit Pferden arbeiten ${ }^{38}$. In Mecklenburg hatte Herr A. zu Beginn der fünfziger Jahre zunächst auch in einem Verein "Körperkultur und Sport“ Pferdesport getrieben, dieses Hobby aber wieder aufgegeben, weil ihm die Eingliederung des Reitsports in die "Gesellschaft für Sport und Technik" und die zunehmend paramilitärische Ausrichtung widerstrebte. Nach der Selbstauflösung des Reitvereins wurde die Gruppe der Konspiration verdächtigt und deshalb überwacht. Grundlos - so Herr A. - denn:

„Es ging ja nur darum, daß wir gesagt haben, wir reiten nicht ins Gelände, und wir machen keinen Meldereiter, wir wollen Sport betreiben, friedlichen Sport und nichts anderes. Es hieß ja nach'm Kriege, kein Deutscher nimmt mehr ein Gewehr in die Hand, und jetzt sollten wir mit Gewehr, Kompaß und Karte - machen wir nicht! So und da haben wir denn - alles verkauft, alle Pferde [. . . ] verkauft. [. . ] Ja, und haben dann Kaltblüter angeschafft, und da hat dann der Vater mit gewirtschaftet, und ich hab mich um kein

${ }^{38}$ Die Liebe der Familie A. zu den Pferden war auch ein überlokales Gesprächsthema: Mit einem weißen Taschentuch hätte man über die Pferde der A.s streichen können, so gut seien sie gepflegt gewesen, berichtete ein Interviewpartner aus einem benachbarten Dorf. 
Pferd mehr gekümmert, hab dann nur noch Landwirtschaft gemacht und mich dem Kuhstall gewidmet, Milchleistung, Kühe schön geputzt, schön die Schweife ausgewaschen das war dann mein Hobby. “ (Interview Herr A.)

Nach dem Eintritt in die LPG, Typ 1, im Jahr 1960 mußten die schweren Pferde aber wieder gegen Warmblüter ausgetauscht werden, weil das Futter für sie zu teuer kam. Vier Jahre später wurde auch der Pferdesport wiederaufgenommen, jetzt aktiv unterstützt von einem Assistenten in der LPG-Führung, dem späteren Vorsitzenden der LPG „Neues Leben“. Aufgrund dieser Interessenkongruenz behielt Herr A. auch nach dem Übergang zu Typ 3 einen eigenen Verantwortungsbereich, in dem seine fachliche Kompetenz geschätzt wurde und ein gewisses $\mathrm{Maß}$ an Selbständigkeit gegeben war; ihm bot sich darüber hinaus sogar eine Chance zur weiteren Professionalisierung im Leistungssport. Für seinen Vater war der Verlust hingegen nicht mehr kompensierbar ${ }^{39}$.

\subsection{Religiosität und Kirche}

Das kirchliche Gemeinschaftsleben besaß traditionell eine wichtige - historisch wie sozial bedingte - Funktion für den inneren Zusammenhalt der Bessarabiendeutschen. In der pietistischen Erweckungsbewegung, die zu Beginn des 19. Jahrhunderts die „Auswandererharmonien " inspirierte ${ }^{40}$, hatte freilich längst eine Ernüchterung eingesetzt und die offizielle evangelisch-lutherische Kirche die Oberhand behalten. Ein Relikt der innerkirchlichen Auseinandersetzungen, in denen religiöse Dissidenz und Schwärmerei noch bis ins 20. Jahrhundert hinein immer wieder aufflammten, waren die Zirkel der "Stundisten“, die sich als Laien mit der Auslegung der Bibel beschäftigten. Das über Konfession und Kirche vermittelte Gruppenbewußtsein hatte, weit mehr als die ethnische Differenz zu den anderen Nationalitäten ${ }^{41}$, den geschlossenen Charakter der deutschen Siedlungen in Südrußland bewahrt und eine Assimilation der deutschen Bauern an ihre orthodoxen russischen und ukrainischen Nachbarn bis zur Umsiedlung im Jahr 1940 weitgehend verhindert ${ }^{42}$. In den bessarabiendeutschen Dörfern bildeten der sonntägliche Gottesdienst, das kirchliche Jahr mit seinen Festtagen, Taufe, Konfirmation, Hochzeit, Begräbnis, nicht

${ }^{39}$ Dem Vater wurde das Futterfahren übertragen - ein Arbeitsfeld, das eine gewisse Zcitautonomie und einen ruhigeren Arbeitsrhythmus erlaubte. So habe auch er sich schließlich in das Unvermeidliche hineingefunden. - „Den alten Leuten fiel's natürlich sehr schwer [...]- man muß sich das nur vorstellen - wie ich Ihnen schon erzählt habe: mit unseren zehn Fingern dies alles erwirtschaftet. [. . .] Am letzten Tag, als wir noch Typ 1 waren, hatten wir sicben Kannen Milch auf der Rampe, das sind 140 Liter Milch, und haben am nächsten Tag schwarzen Kaffee getrunken, wie wir keine Kühe mehr hatten, nicht? Mußtest du von einem Tag auf den andern alles in die großen Ställe bringen, dein Viehzeug, Sauen mit 14 Ferkeln, und - alles war leer, was du mit deinen zehn Fingern erarbeitet hast. Wir, die jungen Leute, konnten uns da reinfinden, no, es wird ja da irgendwie weitergehn, aber die alten Leute!" (Interview Herr A.)

40 Die bessarabische Gemeinde Teplitz war eine Gründung württembergischer „Separatisten“, die sich 1817 auf den Weg zum kaukasischen Bergungsort begeben hatten, um dort als Gemeinde Christi die baldige Wiederkunft des Erlösers zu erwarten (vgl. Anm.10). Unterwegs in einer russischen Quarantänestation festgehalten, hatte sich eine Gruppe von ca. 100 Familien an die russische Regierung gewandt und gebeten, sich in Bessarabien ansiedeln zu dürfen. Vgl. Weiß, Geschichte der Kolonie Teplitz.

${ }^{41}$ Der Anteil der Deutschen an der Bevölkerung Bessarabiens betrug nur etwa $3 \%$. Neben Russen und Ukrainern lebten dort Rumänen bzw. „Moldauer“, Bulgaren, Gagausen, Lipowaner, Juden, Griechen, Armenier, Zigeuner, Polen und Franzosen.

42 Vgl. auch Neutatz, Deutsche Bauern in den Steppen Rußlands, S. 134. 
zuletzt auch das bis zum Ersten Weltkrieg faktisch unter kirchlicher Aufsicht stehende deutsche Schulwesen, generationsübergreifende Strukturen sozialer Kohäsion.

Während der Umsiedlungszeit waren die Möglichkeiten der religiösen Praxis sehr eingeschränkt gewesen. Umso mehr erblickten die bessarabiendeutschen Flüchtlinge nach Krieg, Flucht und Entwurzelung darin wieder einen Halt. Generell hatten die Flüchtlinge an der "religiösen Renaissance“ der Nachkriegszeit einen hohen Anteil. Wie die Inspektionsberichte der evangelisch-lutherischen Landeskirche Mecklenburgs für den Kreis Malchin dokumentieren, bildeten die „Eingewanderten“ einen Großteil des Kirchenvolkes, gerade auch dann, als sich „die Wogen glätteten“ und der Kirchenbesuch der Einheimischen wieder abflaute ${ }^{43}$. Was hier für die Stadt Teterow konstatiert wurde, galt erst recht für die umliegenden Dörfer. Im Inspektionsbericht für die Kirchengemeinde Schwinkendorf heißt es z. B.:

„Im übrigen ist von Tradition nicht mehr zu reden. Die Sonntagsgemeinde hat ein völlig neues Gesicht. Die Flüchtlinge bilden das Hauptkontingent, auch an den Festtagen.“ Und weiter: „Wären wir auf die einheimische Bevölkerung angewiesen, wären die Gottesdienste einfach zum Erliegen gekommen. ${ }^{\text {“4 }}$

Ging in den fünfziger Jahren in der Stadt der volkskirchliche Charakter mehr und mehr verloren, was sich an der schrumpfenden Zahl der Kirchenbesucher, der Teilnehmer an Abendmahl und Konfirmation ablesen ließ, so schlug sich diese Tendenz auf dem Lande noch nicht so deutlich nieder ${ }^{45}$. In den mecklenburgischen Bessarabierdörfern Grambzow und Schwinkendorf waren Gottesdienste, Bibelstunden und andere kirchliche Veranstaltungen noch überdurchschnittlich gut besucht, und auch nach der Einführung der Jugendweihe gingen die meisten Jugendlichen zum Konfirmandenunterricht $^{46}$. Gleichwohl nahm der sonntägliche Kirchenbesuch auch hier seit den fünfziger Jahren mehr und mehr ab. Mit ein Grund dafür war - den Pfarrberichten zufolge - die Überlastung des Landvolks, auch mit Sonntagsarbeit, die auf dem Lande seit drei Jahrzehnten üblich war. Nach der Einführung der LPG wurde es für die einzelnen, auch für die Frauen, noch schwieriger, sich den Sonntag freizuhalten. Zwar gab es keine unmittelbare Behinderung der Gottesdienste, doch hielten Arbeitseinsätze, Produktionsberatungen, Einwohnerversammlungen und Veranstaltungen anderer Art Erwachsene und Kinder immer wieder vom sonntäglichen Kirchenbesuch ab. Auch an anderen hohen kirchlichen Feiertagen wie Karfreitag, Gründonnerstag u. a. versammelte sich nur noch ein kleiner Kreis in der Kirche.

${ }^{43}$ LAS, Inspektionsberichte der Evangelisch-lutherischen Landeskirche in Mecklenburg (im folgenden: Inspektionsberichte), Gemeindeberichte Teterow 1945-1965, hier: 1945/46 und 1947.

${ }^{44}$ Ebenda, Gemeindebericht Schwinkendorf 1945-47, Bl. 37 und 59.

${ }^{45}$ Dem Gemeindebericht Teterow 1963/64 (vgl. Anm. 41) zufolge nahmen in den Dörfern damals noch gut 95 Prozent der Kinder am Unterricht teil, in Teterow waren es hingegen nur noch 3040 Prozent. - Der Schwinkendorfer Pfarrer Heinrich konstatierte in seinem Bericht für die Jahre 1954-56, das Gemeindeleben basiere auf einem „Kern ernster Christen von kirchlicher Haltung“ und zeige auch gegen die antichristliche Propaganda eine "gewisse Widerstandskraft". In den Randsicdlerdörfern sei allerdings ein „Abbröckeln“ bemerkbar. Vgl. LAS, Inspektionsberichte, Gemeindebericht Schwinkendorf 1954-56.

${ }^{46}$ Seit 1959 kam es zu ersten ernsthaften Störungen des Konfirmationsunterrichts. Da viele Familien für sich und ihre Kinder Nachteile befürchteten, wenn sic die Jugendweihe ablehnten, strebte dic Kirchenführung mit der Verlegung der Konfirmation auf einen Termin im Herbst eine Kompromißlösung an, um beides zu ermöglichen. - In der Honecker-Ära ging die Zahl der Konfirmationen dann rapide zurück (vgl. Interview Herr K.). 
Die Kirchgangshäufigkeit ist freilich nicht das einzige Merkmal einer volkstümlichen Frömmigkeit. So wurden bei den Bessarabiern der älteren Generation auch andere, z. T. überlokale christliche „Gemeinschaften“ gepflegt, mancherorts auch die „Stunden“ wiederaufgenommen oder häusliche Andachten mit den aus der Heimat mitgebrachten Gebets- und Gesangbüchern abgehalten ${ }^{47}$. An den Bibelstunden beteiligten sich übrigens Bessarabiendeutsche wie Mecklenburger. Aus Hohen Pritz wird berichtet, daß dort eine Reihe von Missionsveranstaltungen großen Zulauf gefunden habe - mit der Folge, daß die für diesen Ort vorgesehene Auszeichnung „Sozialistisches Dorf“ an die Nachbargemeinde weitergereicht worden $\operatorname{sei}^{48}$.

In den ersten Nachkriegsjahren scheint es zwischen Einheimischen und Flüchtlingen auch im kirchlichen Bereich einige Irritationen gegeben zu haben. So beklagt der Schwinkendorfer Pfarrer 1948/49, daß die Kirchlichkeit der Flüchtlinge wider Erwarten nicht über die Unkirchlichkeit der Eingesessenen gesiegt habe, sondern umgekehrt, nun auch die Flüchtlinge sich der Kirche entfremdeten:

„Die schönste Hoffnung, die wir auf diese frommen Menschen setzten, hat getrogen. Man wird mit offenen Armen von ihnen aufgenommen, aber zur Kirche kommen sie auch nicht. Freilich sind es immerhin noch ein paar mehr von ihnen als von den unseren in der Kirche. “49

Eben dieser Pfarrer berichtete freilich wenig von den Anstrengungen zu ihrer Integration in die Kirchengemeinde; er hatte vielmehr „daraufgehalten, daß die vielen Flüchtlinge nicht ihre Gtd. [Gottesdienst-]Ordnung in unsere heimische hineintragen " und verbuchte es als Erfolg, daß dies auch gelungen sei ${ }^{50}$.

Wie den späteren Gemeindeberichten zu entnehmen ist, haben die Bessarabiendeutschen vor allem bei Begräbissen ihrer Landsleute noch lange Zeit an ihren heimatlichen Bräuchen festgehalten:

„Besonders gut ist die Beteiligung am Gesang, wenn bessarabische Umsiedler in größerer Zahl beteiligt sind, das ist vor allem bei Leichen aus Langwitz, bisweilen auch aus Schwinkendorf und Christinenhof der Fall. [. . .] Manchmal besonders bei Bessarabiern und deren Verwandten stimmt das Gefolge nach Ende des kirchlichen Aktes spontan noch weitere geistliche Lieder an. “ 51

Geistliche Lieder aus der alten Heimat wurden aber nicht nur im kirchlichen Raum, sondern auch bei Familienfeiern und dörflichen Festen gesungen ${ }^{52}$.

Obwohl die Bedeutung der Kirche für den dörflichen Alltag in den sechziger Jahren immer weiter zurückgedrängt wurde, erhielt sich etwa in Schwinkendorf ein ortsgebundenes Gemeinschaftsgefühl, in dem auch die Kirche einen Platz behielt. Im Kirchenrat aktive Bessarabier aus Langwitz und Schwinkendorf regten Selbsthilfeaktionen an, für die in den Dörfern des Kirchspiels Spendengelder gesammelt wurden und für die auch die Dorfjugend freiwillige Arbeitseinsätze leistete: den Bau einer Leichenhalle, einer neuen Friedhofsmauer, die Umdeckung des Kirchendaches. Die reiche Schwinkendorfer

${ }^{47}$ Vgl. LAS, Inspektionsberichte, Kirchengemeinde Schwinkendorf 1945-1964.

${ }^{48}$ Das neue Kulturhaus wurde nun in Mestlin errichtet (vgl. Interview Frau M.).

49 Vgl. LAS, Inspektionsberichte, Gemeindebericht 1948/49.

50 Im vorhergehenden Gemeindebericht war noch davon die Rede, daß sich die kirchliche Lage völlig verändert habe und die reguläre Gemeinde zur "Siedlergemeinde“ geworden sei (vgl. LAS, Inspektionsberichte, Gemeindeberichte Schwinkendorf 1945-1949).

51 Vgl. LAS, Inspektionsberichte, Gemeindebericht Schwinkendorf 1960-62.

52 Vgl. Interview Herr K. 
LPG brachte die Gelder auf, um das baufällige Pfarrhaus zu restaurieren; ihre Brigaden beteiligten sich auch an den Sanierungsarbeiten am Kirchendach ${ }^{53}$.

\subsection{Heimatliche Bräuche im Wandel}

Das bessarabische Gemeinschaftsleben wurde in mecklenburgischen Bessarabier-Dörfern noch jahrelang gepflegt. Man feierte die Feste im alten Stil - ob das nun Hochzeiten waren oder Erntefeste, der 1. Mai oder der Internationale Frauentag - und sang die alten Lieder. Gesungen wurde bei den Bessarabiendeutschen viel und gern - vor allem Volksund Kirchenlieder - und auch mit der Ziehharmonika aufgespielt. An den Wochenenden traf sich die Dorfjugend zu Spiel und Tanz. Hier kam es in den ersten Nachkriegsjahren oft zu heftigen Auseinandersetzungen und Schlägereien zwischen einheimischen Jugendlichen und Flüchtlingen, in denen zumeist Rivalitäten um Mädchen und Platzkämpfe ausgetragen wurden. Den jungen Bessarabiern haftete deshalb auch der Ruf der „Messerstecher" $a^{54}$. Die Abnahme dieser Konflikte durch Verheiratung und Einheirat läßt sich wohl als Zeichen fortschreitender Integration interpretieren; bereits in der nachfolgenden Generation erfolgte die Gruppenbildung unter den Jugendlichen nach anderen Kriterien.

Die Erosion der bessarabischen Milieus setzte Ende der fünfziger/Anfang der sechziger Jahre ein. Jetzt saß man abends zuhause vor dem Fernseher und nicht mehr draußen auf dem „Hofbänkle“ oder unter den Kastanien auf dem Dorfplatz vor dem abgerissenen Herrenhaus.

Wie es früher in Langwitz war, erzählt Herr K.:

„Die sind ja jeden Tag zusammengekommen, die Alten, so wie da in Teplitz auf'm Bänkle [...] Die Frauen auch, wenn sie Zeit hatten. - Also wir haben vorn am Zaun ne Bank, und da ist mein Vater draußen gesessen, jeden Abend, wenn er Zeit hatte. Mein Vater, der war schon älter, der war Invalidenrentner [...], da kamen alle [gemeint sind die Bessarabier], die kamen hin, und dann hat's ein Glas Wein gegeben - mein Vater hatte immer Wein, wir hatten ja diesen Obstwein selber gemacht, weil sie ja keinen Wein hatten - so, dann haben sie eben gessen und bei einem Glas Wein, viel haben sie nicht getrunken, aber dann haben sie eben geplauscht [...]. - Das hat sich bei uns immer abgespielt, das war so, daß wir das als Kinder immer miterlebten, da wurde eben dieses Schwäbisch gesprochen und wurde immer über die alte Heimat gesprochen, immer. Da haben wir eigentlich sehr viel mitbekommen." (Interview Herr K.)

In Grambzow traf man sich sonntags früh; in späteren Jahren kamen auch die Mecklenburger dazu:

„Ja, da wurde viel zusammengegangen, weil das Fernsehen damals noch nicht war das macht viel aus!" (Interview Herr O.)

Nicht nur das Fernsehen, auch die Chancen einer größeren Mobilität durch den zunehmenden Autoverkehr trugen in den sechziger Jahren zur Veränderung des dörflichen Gemeinschaftslebens bei. Zugleich fand aber auch durch den Ausbau der Großlandwirt-

${ }^{53}$ Vgl. Interview Herr K., Herr A. - Aus dem Gemeindebericht der Kirchgemeinde Schwinkendorf für 1963/64, der die Erneuerung des Pfarrhausdaches und die Umdeckung des Kirchendaches erwähnt, geht nichts über die Finanzierung dieser Arbeiten hervor.

${ }^{54}$ Interview Herr U. - Die Neigung zu gewalttätigen Auseinandersetzungen ist auch ein Thema in den Gemeindeberichten des Schwinkendorfer Pfarrers Heinrich; sie sei hier größer als anderswo. "Schlägereien kommen häufig vor, die auch oft in Messerstechereien ausarten." (LAS, Inspektionsberichte, Gemeindebericht vom 20.6. 1954.) 
schaft in immer größeren Einheiten, die Trennung von Tier- und Pflanzenproduktion nach sowjetischem Vorbild und das Zusammenlegen von Dörfern ${ }^{55}$ ein tiefgreifender Wandel der Produktions- und Kommunikationsstrukturen auf dem Lande statt. Ziel der KAPs („Kooperative Abteilung Pflanzen- bzw. Tierproduktion“) war es, industriemäßige Produktionsmethoden in der Landwirtschaft einzuführen ${ }^{56}$ und die Lebensbedingungen auf dem Dorf an die der Stadt anzugleichen. Längst war die junge Bessarabier-Generation, die in der kollektivierten Landwirtschaft keine Perspektive mehr sah, in andere Berufe abgewandert. Auf den Dörfern blieben die Alten zurück, deren Reihen sich mit der Zeit lichteten. Ganze Familien waren zudem „bei Nacht und Nebel“ nach Westdeutschland übergesiedelt ${ }^{57}$.

An den Erntefesten, die in allen Interviews ausführlich geschildert werden, hatte sich auch die einheimische Bevölkerung beteiligt. Schon früher waren Erntefeste gefeiert worden, doch trugen sie einen anderen Charakter: Es gab ein vom Gutsbesitzer ${ }^{58}$ ausgerichtetes Gesindeessen, ein „Ausköst“, und wohl auch „Tanz op de Deel“, aber keine Umzüge mit festlich geschmückten Ernte- und Pferdewagen. Wie die Festzüge in Langwitz aussahen, beschreibt Herr K.:

„Also Erntefest, das war was Schönes früher. Da wurden die Wagen geschmückt, richtig mit Ernterzeugnissen - mit den Erntekronen - und das haben immer die Bessarabier in Regie gehabt, also wunderschön haben die diese Wagen geschmückt, und dann die Rechen und Gabeln, alles wurde geschmückt und dann [...] gab es einen Pferdewagen mit der Kapelle, und dahinter war der Wagen mit den Kindern, den kleinen Kindern, die in den Kindergarten gingen, und denn ging das ganze Dorf hinterher, jeder mit ner geschmückten Sache, das ganze Dorf. “59 (Interview Herr K.)

Mit festlichen Umzügen wurde auch der 1. Mai gefeiert, der Dorfplatz gestaltet und mit Birkengrün geschmückt. (Bereits in Teplitz war der Wettstreit zwischen „Ober-“ und „Unterdorf“ um den schönsten Mai- und Pfingstbaum Tradition gewesen.) Die kurzen Reden enthielten sich hier im allgemeinen jeder Politik.

Mancherorts wurde auch der Brauch des „Eierlesens“ am Ostermontag wiederaufgenommen. Er war von den württembergischen Auswanderern nach Bessarabien mitgebracht worden, dort aber - wie manch anderes harmlose Vergnügen - von den pietistischen Geistlichen und Stundenbrüdern unterdrückt worden. In den dreißiger Jahren wurde er von der jungen Generation, die gegen die altväterliche Sittenstrenge rebellierte, reaktiviert und offenbar auch noch nach 1945 für kurze Zeit praktiziert. Länger als das „Eierlesen“ hielt sich in den Bessarabier-Dörfern das „Pelzmärtle“ - eine Art Nikolaus, der grausamerweise nach der Weihnachtsbescherung am Heiligabend mit der Rute durch das Dorf ging, um unartige Kinder zu züchtigen. Diese Figur mußte schließlich (wie üb-

55 Die Schwinkendorfer KAP faßte 13 Dörfer zusammen und bewirtschaftete ca. 8000 ha.

${ }^{56}$ Der dritte Entwicklungsabschnitt in der Landwirtschaft der SBZ/DDR sei "durch dic zentralgesteuerte kooperative Herausbildung sozialistischer landwirtschaftlicher Großbetriebe charakterisiert, die seit 1967 zum industriemäßig produzierenden Spezialbetrieb der Landwirtschaft führte." (DDR-Handbuch, Bd. 1, S. 785.)

57 Man nannte dies „LPG, Typ vier: Der Bauer ist fort, der Acker bleibt hier“ (vgl. Interview Herr G.).

58 Neuerdings versucht ein aus der früheren Gutsbesitzerfamilie stammender "Wiedereinrichter“ durch die Veranstaltung von Erntefesten und Osterfeuern wieder mit der Dorfbevölkerung ins Gespräch zu kommen (vgl. FAZ vom 6.6. 1996).

59 Interview Herr K. 
rigens auch die mecklenburgischen Kinderschreck-Varianten, z. B. die „Neujahrsfrau“) in den sechziger Jahren liberaleren Erziehungsvorstellungen weichen. Erzählt wird auch von der Sitte des „Heilige-Drei-Königssingens“ am 6. Januar, das ebenfalls bis Anfang der sechziger Jahre üblich war.

Es überrascht nicht, daß solche und ähnliche Bräuche in der zweiten Generation oft kaum noch erinnert und auch nicht weiter überliefert werden. Wichtiger für Zusammenhalt und Identifikation sind hier andere Charakteristika der Alltagskultur, etwa die Vorliebe für die bessarabische Küche, die z. T. auch auf die mecklenburgischen Ehepartner und die Kinder abgefärbt hat ${ }^{60}$. Der schwäbische Dialekt ist der zweiten Generation noch gut vertraut, obwohl die Eltern zumeist darauf achteten, daß ihre Kinder Hochdeutsch sprachen, um ihnen Schwierigkeiten in der Schule zu ersparen. Untereinander „schwätzen“ die alten Bessarabier jedoch auch heute noch immer schwäbisch. Die Lust am Singen ist auch in der zweiten Generation noch vorhanden, vor allem bei den gelegentlichen Treffen der Jugendfreunde oder der Verwandtschaft. Selbst örtliche Musikkapellen integrierten schwäbische Lieder wie „Auf dem Wase graset d' Hase“ oder „A Büschele Haberstroh“ in ihr Repertoire. Offenbar haben ältere Bessarabier es gern gesehen, wenn die Jugend Musik machte und sie dabei auch großzügig finanziell unterstützt.

\subsection{Die zweite Generation - weg vom Dorf!}

Die Kinder der interviewten mecklenburgischen Bessarabier sind selbst dann, wenn sie sich für die Landwirtschaft interessierten, meist nicht auf dem Lande geblieben. Einige wurden Facharbeiter, Handwerker, gingen zum Überseehafen oder zur Werft; andere arbeiten in Angestelltenberufen, als Ingenieure, Lehrer und Berufsschullehrer oder (nach der Wende) auch als selbständige Unternehmer.

Berufswahl und -chancen der Kinder waren nicht nur von Leistung und Interesse abhängig, sondern wurden auch durch ihre familiäre Situation und die parteioffizielle Linie zur Arbeitskräftelenkung mitbeeinflußt. Wegen der christlichen Orientierung ihrer Eltern hatten einige von ihnen Nachteile: So durfte z. B. Herr K., dessen Vater Kirchenältester war, trotz seiner guten Leistungen nicht zur EOS gehen; erst als seine Mutter öffentlich drohte, deshalb nicht zur Wahl zu gehen, lenkten die Schulbehörden ein. Die Tochter von Frau T., in deren Wohnung regelmäßig „Stunden“ abgehalten wurden, erhielt keine Genehmigung zum Studium: „Sie paßte nicht rein in unseren Staat“61. Frau E. wurde von Lehrern unter Druck gesetzt, ihre Söhne zur Jugendweihe zu schicken, um ihnen eine Lehrstelle zu sichern. Trotz der Weigerung fanden aber auch sie einen Beruf ${ }^{62}$.

Schwierig war die Situation für die Kinder der Einzelbauern, die neben der Schule voll in den familiären Arbeitsprozeß eingespannt waren. Herr K. schildert das für seine älteren Schwestern, die morgens, bevor sie mit dem Zug zur Schule fuhren, noch zwei Stunden aufs Feld gehen oder andere Arbeiten verrichten mußten:

60 Paprika oder Melonen wurden, wenn sie in den DDR-Konsumgeschäften crhältlich waren, von den Bessarabiern kistenweise aufgekauft und nach bessarabischen Rezepten zubereitet. Die vielfältigen Variationen von Mehlspeisen (wie Knöpfle, Küchle, Dampf- und Schupfnudeln, Strudel, Krapfen, Piroggen und Platschinten u. a.m.), die die Großmütter beherrschten, waren bei den Enkelkindern sehr begehrt, und die Gerichte des Balkans und der Schwarzmeerküste brachten in die mecklenburgische Küche einen Hauch von Exotik.

${ }^{61}$ Interview Frau T.

62 „Einen Beruf hatten sie alle, so wie jetzt [gemeint ist die Zeit nach der Wende] war's nicht! Sie mußten aber auch nehmen, was ihnen angeboten wurde." (Interview Frau E.) 
„Für die war es echt schlimm! Für die Generation war es ne schlimme Zeit. Die wurden neben ihrer Tätigkeit in der Schule voll eingespannt, weil jede Hand gebraucht wurde, damals. Und da kannte unser Vater kein Pardon, das muß ich ganz ehrlich sagen. Auf das Familienleben hat sich das nicht günstig ausgewirkt." (Interview Herr K.)

Der Vater von Frau S. war noch im April zum Volkssturm eingesetzt worden und kam erst zwei Jahre später aus der Gefangenschaft zurück, in der er sich eine TBC-Erkrankung geholt hatte. Dem Vater zuliebe, der mit Leib und Seele Bauer war, blieben die Kinder auf dem Hof, um die Wirtschaft auf den gleichen Stand zu bringen wie die anderen, obwohl sie eigentlich andere Berufswünsche hatte. Als sich die Bildung der LPG abzeichnete, wurde es für die Bauernkinder immer schwieriger, vom Land wegzukommen. Frau S. betrachtete sich als "gerettet", als es ihr nach dem Tod ihres Vaters gelang, eine Ausbildung in einer landwirtschaftlichen Berufsschule abzuschließen und eine externe Meisterprüfung abzulegen. Ihrem Bruder gelang dies nur dadurch, daß er sich zur Polizei meldete. Auch die Schwestern von Herrn K. hatten, wegen der Aktion „Wer vom Dorf kommt, soll auch im Dorf bleiben“, trotz guter Zeugnisse nicht die Möglichkeit, eine höhere Schule zu besuchen. Ihr Vater drängte aber darauf, daß die Mädchen aus dem Dorf gingen und Berufe als Angestellte ergriffen. Erst in späteren Jahren ergab sich für vom Land kommende Jugendliche die Chance, sich für Leitungsfunktionen in den LPGs und KAPs zu qualifizieren; so sollte der Sohn von Herrn A. in der Tierproduktion bleiben und schloß nach einer Ausbildung zum Zootechniker mit Abitur ein Landwirtschaftsstudium ab. Das kulturelle Kapital seiner Familie nutzend, betreibt auch er heute Pferdesport, züchtet Pferde und besitzt einen Reiterhof.

\subsection{Interessenvertretung und politisches Vereinsleben}

Dort wo die Bessarabiendeutschen eine starke Gruppe darstellten, haben sie auch versucht, ihre Interessen zur Geltung zu bringen und sich gegen Entscheidungen und Anordnungen der Staatsorgane bzw. der SED, die sie direkt betrafen, zur Wehr zu setzen. So berichtet z. B. der Landrat von Malchin im Juli 1951 über eine Bauernversammlung in der Gemeinde Groß-Köthel, bei der "gestützt auf den Wortführer die Umsiedler aus Grambzow (Bessarabier) wie ein Block" aufgetreten seien und sich gegen Bestimmungen des Umsiedlergesetzes und Entscheidungen der „Kreisdifferenzierungskommission“ gewandt hätten. Bereits im Mai 1951 hatten sie deshalb eine Beschwerde an den Präsidenten der DDR, Wilhelm Pieck, gerichtet. Der Grambzower Gemeinderat, die Vereinigung der gegenseitigen Bauernhilfe (VdgB) und der Bürgermeister hätten sich in dieser „lebhaften Auseinandersetzung " völlig passiv verhalten. Schon vorher habe der Ortsteil Grambzow bei der Zusammenlegung mehrerer Dörfer zu einer Zentralgemeinde „große Schwierigkeiten“ gemacht; diesbezügliche Beschwerden seien unberechtigterweise sogar mit dem inzwischen ungültigen Dienstsiegel der Gemeinde Grambzow versehen worden. „Diese Schwierigkeiten haben ihre Ursache darin, daß der größte Teil der Einwohner Grambzows Umsiedler aus Bessarabien sind, die versuchen ihre eigenen Wege zu gehen $[\ldots]^{\star 63}$. Als Konsequenz dieser Auseinandersetzungen wurde nun gefordert, ein besonderes „Augenmerk“ auf die Gemeinde Groß-Köthel zu legen, die „politische Aufklärungsarbeit“ in den Ortsteilen zu verstärken und „durch beharrliche Aufklärung und

${ }^{63}$ Der Rat des Kreises Malchin, Dezernat Leitung, an das Staatssekretariat für Erfassung und Aufkauf landwirtschaftlicher Erzeugnisse, 24. 7. 1951, MLHA, Rat des Kreises Malchin, Bd. 28. 
Überzeugung die Bauern mit unseren Gesetzen vertraut" zu machen. Die Umsiedler in Grambzow besäßen im übrigen einen wesentlich besseren Viehbestand als die anderen Ortsteile und müßten deshalb verstärkt zur Erfassung und Ablieferung herangezogen werden.

Sofern sich die Bessarabier in den mecklenburgischen Dörfern politisch interessiert und betätigt haben, waren sie zumeist Mitglieder der Demokratischen Bauernpartei. Die Blockpolitik der SED war insofern durchaus erfolgreich, als es ihr gelang, die von ihr geschaffene Satellitenpartei als Interessenvertretung der Landbevölkerung darzustellen ${ }^{64}$. Wie die Mecklenburger betrachteten auch die Bessarabier die DBD offensichtlich weniger als eine politische Partei denn als eine Art „Verein“, in dem die Bauern landwirtschaftliche Themen, Beschaffungsprobleme u. a.m. diskutierten und im übrigen eine gesellige Veranstaltung sahen. So beschreibt es Herr U.:

„Die halben Bessaraber waren doch in der DBD, da haben sie dann abends [...] im Krug gesessen und einen getrunken und über Pferdezucht oder irgendwas geredet, Privatgespräche." (Interview Herr U.)

Manche, wie der Vater von Herrn K., sind aus der DBD bald wieder ausgetreten, als sie feststellten, daß diese Organisation keine Neuauflage des Teplitzer „Vereins“"65, sondern eine „SED auf dem Lande“ war. Andere, wie Herr A., traten gar nicht erst in die Bauernpartei ein, weil sie deren Schwäche und die Abhängigkeit von der SED sahen: Die DBD müsse sowieso nach der Pfeife der SED tanzen; wenn man überhaupt etwas Politisches bewirken wolle, müsse man dort eintreten. Daß er selbst parteilos blieb, bereitete ihm in seinem Beruf keine Schwierigkeiten. Frau S. wäre gerne in die DBD eingetreten, um ihr „Brot nicht zu verlieren“, durfte aber von den „Hilfskommunisten“ nicht aufgenommen werden, weil sie für die SED und eine parteimäßige Weiterqualifizierung geworben werden sollte. Sie wehrte sich dagegen, indem sie sich als Schöffin zur Verfügung stellte, und bedrängte ihren Abteilungsleiter, ihr nicht die „letzte persönliche Freiheit" zu nehmen, da sie auch noch ihre kranke Mutter zu versorgen habe ${ }^{66}$.

Bei den Bessarabiern gab es freilich auch einige SED-Mitglieder; aus einer Familie gingen z. B. ein Parteisekretär, der in der örtlichen LPG auch eine Betriebsparteiorganisation aufzubauen versuchte, sowie ein Funktionär in der SED-Kreisleitung hervor. Manche Landsleute begegneten diesen "Genossen" zwar mit einer gewissen Distanz; sofern sie sich aber im Rahmen der Interessengemeinschaft des Dorfes bewegten oder sich - etwa als Bürgermeister - besonders für ihren Ort einsetzten, wurden ihre Bemühungen auch geachtet. Einige der Jüngeren waren - wie sie sagen - der SED beigetreten, um einen Studienplatz zu erhalten oder beruflich voranzukommen; nur einem von ihnen gelang es, sein Parteibuch wieder zurückzugeben.

\section{Die Wende 1989}

Auf dem Weg in eines der mecklenburgischen „Bessarabier“-Dörfer, auf dem Feldweg zu einem abgelegenen Gehöft namens Christinenhof, begegnete ich einem alten Mann auf einem Fahrrad und fragte ihn nach dem Weg: „Wo kommen Sie her?“ Er sagte: „Oh -

${ }^{64} \mathrm{CDU}$ und LDPD besaßen in dieser Region keine ausgebauten Stützpunkte.

${ }^{65}$ Im Jahr 1925 wurde in Teplitz der Verein "Eintracht “ gegründet, der vor allem ein Bildungs- und Geselligkeitsverein war (vgl. Weiß, Geschichte der Kolonie Teplitz, S. 292).

66 Interview Frau S. 
ich komme von weit her [...]" Er erzählte dann, daß er aus Ostpreußen stamme und nach dem Krieg hier in Mecklenburg eine Siedlung bekommen habe. Der Anfang sei nicht leicht gewesen, und dann die LPG! Doch das sei schon lange her, und nach dem letzten Umsturz - gemeint war die Wende 1989 - sei wieder alles ganz anders gekommen. Wieder einmal müsse man von Neuem beginnen, wenn dies nun auch Sache der Jüngeren sei. In diesem Gespräch zeigte sich eine Erzählstruktur, die auch die Interviews mit bessarabiendeutschen Umsiedlern der älteren Generation durchzieht: Die erlebte Geschichte mit ihren historischen Brüchen ist präsent, und der politische Umbruch des Jahres 1989 fügt ihr noch einen Refrain hinzu; er überformt die Erinnerungen und ihre Interpretation und aktualisiert die Erfahrungen des Verlusts.

Die Biographien sind in dieser „Erlebnisgeneration“ durch vier tiefe historisch-politische Einschnitte geprägt. Die heute 75 bis 85 jährigen (d.h. Angehörige der Jahrgänge 1912 bis 1922) waren im Jahr der Umsiedlung (1940) 18 bis 28 Jahre alt. Sie hatten in ihren Heimatorten gerade damit begonnen, sich eine Existenz aufzubauen, eine „Wirtschaft", d. h. Haus und Hof, oder eine andere berufliche Perspektive, eine Familie. Die Umsiedlung nach dem Hitler-Stalin-Pakt, der Abschied von der Heimat und der Krieg gegen die Sowjetunion bedeuteten für sie einen ersten tiefen Bruch. Anfang 1945 wieder ein abruptes Ende: Flucht, Trennung oder auch Tod von Familienangehörigen, Freunden und Nachbarn, Kriegsgefangenschaft und Verschleppung, der Verlust der gesamten Habe, Not, Hunger, Fremdheit und Suche nach einer neuen Bleibe. Der schwer erarbeitete, bescheidene Wohlstand der „Neubauern“ in der SBZ/DDR ging durch die Kollektivierung der Landwirtschaft wieder verloren.

Schließlich brachte die Wende 1989 - wiewohl begrüßt und erwünscht - neue Lebensverhältnisse und Freiheiten, aber auch erneut Verunsicherungen, Ungerechtigkeiten und Entwertungen mit sich. So erhielten etwa die LPG-Mitglieder nach der Umwandlung der LPGs in GmbHs nur einen Teil der Gelder zurück, die ihnen beim Eintritt damals zwangsweise abverlangt worden waren ${ }^{67}$. Was sie über Jahrzehnte erwirtschaftet haben, ihre Arbeitsleistung, scheint nun ohne Wert. Selbst wenn das Bodenreformland zurückgegeben wird, ist ein nochmaliger Neuanfang in der Landwirtschaft für diese Generation, aber auch für ihre Kinder nicht mehr möglich ${ }^{68}$. Deren Perspektive wird nach dem Niederbrechen von Betrieben und Werften zudem von der drohenden Massenarbeitslosigkeit überschattet. Unerwartete Probleme tauchen auf, die individuell gelöst werden müssen: So hat z. B. Frau K. beim Tod ihres Mannes, dessen zweite Frau sie war, zwar die Siedlung übernommen, ist aber nicht ins Grundbuch eingetragen worden - mit den entsprechenden Folgen für Entschädigung und Vererbbarkeit ${ }^{69}$. Die Angestelltentätigkeit von

67 Von den LPG-Nachfolgern wurden nur die Beträge für das lebende Inventar rückerstattet, $z$. T. auch ein kaum nennenswerter „Inventarbeitrag“ ausbezahlt.

68 "Was soll mein Sohn denn anfangen, wenn ich ihm das wiedergeb? Ich hab's ihm ja gegeben! Wenn der Bauer spielen möchte, da müßt' er - unter 50 ha kann hier keiner leben." (Interview Herr O.) - Bodenreformland kann nur von denen verpachtet, vererbt oder verkauft werden, die es ehedem auch genutzt haben. Wer Bodenreformland zurückerhält, hat auf die einheitliche Lastenausgleichszahlung für Flüchtlinge und Vertriebene in der ehemaligen DDR in Höhe von 4000 DM keinen Anspruch.

69 Ähnliche Fälle sind nicht selten, da die Bedeutung des Grundbuches in der DDR mit der in der alten Bundesrepublik nicht vergleichbar ist. Überschneidungen und Unterschiede zwischen dem DDR-Zivilrecht und der bundesdeutschen Rechtsordnung einschließlich der komplizierten Übergangsregelungen für das Bodenreformland sind für juristische Laien kaum durchschaubar (vgl. Intervicw Frau KM). 
Frau S. beim Landwirtschaftsamt des Rats des Kreises, die ihre einzige Chance war, um dem Land zu entfliehen, wird als „staatsnahe Tätigkeit“ eingestuft, weshalb ihre Rente gekürzt wird.

Die Enttabuisierung des „Umsiedler“-Themas hat in den neuen Bundesländern generell zu einer längst fälligen Sensibilisierung der Öffentlichkeit für die Schicksale der Flüchtlinge und Vertriebenen geführt; sie ermöglicht es diesen nun auch, offener über ihre Herkunft zu sprechen. Dieses Bedürfnis ist in den Städten, wo die ohnehin kleine Gruppe der Bessarabiendeutschen viel zerstreuter lebt, möglicherweise noch größer als in den mecklenburgischen Bessarabier-Dörfern, in denen sich ein dichteres Milieu und Heimatgefühl herausbildete ${ }^{70}$. Die Tatsache, daß sich zum ersten „Bessarabischen Kirchentag“ im Mai 1994 im Güstrower Dom über 500 Menschen versammelten, spricht für sich. Neue Informationsmöglichkeiten, die Treffen mit Landsleuten, nicht zuletzt auch die Reisen ins heutige Bessarabien und die Beschäftigung mit den Problemen der heute in diesem südosteuropäischen Raum lebenden Menschen haben auch bei Angehörigen der zweiten Generation ein Interesse ausgelöst, das über die materiellen Aspekte der Lastenausgleichsregelung für die neuen Bundesländer bzw. die Nutzung des Durchsetzungspotentials der Vertriebenenverbände hinausgeht, und das neue Identifikationen, Verbindungen und "Wahlverwandtschaften" stiftet. Andererseits könnten die sozialen Strukturveränderungen im Zuge der Wende 1989 aber auch dazu führen, daß sich die Auflösung der verbliebenen bessarabischen Rest-Milieus in den mecklenburgischen Dörfern noch beschleunigt.

\section{Resümee}

Integration erweist sich in dem hier beschriebenen Ausschnitt als ein Langzeitprozeß, der von den Beteiligten immer wieder neue Anpassungs- und Reflektionsleistungen erfordert. Aufgrund der politischen Verhältnisse in diesem Teil Deutschlands war die Integration der Bessarabiendeutschen in Mecklenburg tatsächlich „ein steiniger Weg“; dennoch haben sie sich „den Bedingungen des Aufnahmelandes gestellt" und „sich mit ihrer ganzen Kraft eingebracht" ${ }^{\text {"1 }}$.

Betrachtet man die Stationen dieser „kollektiven Biographie“ aus heutiger Sicht unter dem Aspekt der Integration in der SBZ/DDR, so lassen sich einige Punkte herausgreifen und systematischer diskutieren.

1. Zunächst verwundert es, daß - trotz der in Deutschland weit verbreiteten Angst vor den Russen - so viele Bessarabiendeutsche in der Ostzone geblieben sind und selbst Landsleute, die schon in den Westzonen Fuß gefaßt hatten, zum Nachzug bewegen konnten. Erst wenige Jahre zuvor hatten sie beim Einmarsch der Roten Armee in Bessarabien im Sommer 1940 ihre eigenen Erfahrungen gemacht, und die Prophezeiungen russischer Offiziere, man werde sich ohnehin bald in Deutschland wiedersehen, waren in ihrem kollektiven Gedächtnis längst zum Stereotyp geronnen. Zudem hatten die Geschehnisse bei der Einnahme von Teterow durch die Sowjetarmee in der Nacht vom 30. April

70 „In der Stadt ist es vielleicht noch etwas anders als hier auf dem Dorf. Gerade in Langwitz, wo so viele Bessaraber da sind, da hat man vielleicht dieses Heimatgefühl noch mehr gehabt! Aber meine Tante in Güstrow - die haben sich nie integrieren können in diesem Land." (Interview Herr K.).

${ }^{71}$ Nitschke, Das Leben ging auch in Mecklenburg weiter, S. 78. 
zum 1. Mai 1945 und in der darauffolgenden "wilden Zeit“ bei der Bevölkerung der Stadt und der umliegenden Dörfer panikartige Reaktionen und einen tiefen Schock ausgelöst: Allein in Teterow nahmen sich damals ca. 400 Menschen das Leben ${ }^{72}$.

Ein Ausweichen in den Westen war freilich in der unmittelbaren Nachkriegszeit für viele gar nicht möglich, sei es aus familiären Gründen oder weil sie keine Zuzugsgenehmigungen erhielten. Dank der unkonventionellen Initiative Karl Rübs ${ }^{73}$ gelang es allerdings einigen Bessarabiendeutschen, bis Ende 1946 aus der Ostzone nach Württemberg überzusiedeln. Andererseits war die Attraktivität der Bodenreform, die seit dem Spätsommer 1945 anlief und auch den Flüchtlingen eine neue Existenzgrundlage versprach, auch und gerade für die bessarabiendeutschen Bauern so groß, daß sie ihre Bedenken zurückstellten. Dennoch blieb die Situation für sie noch solange prekär, wie sie fürchten mußten, von sowjetischen „Repatriierungskommandos“ aufgegriffen und nach Rußland verschleppt zu werden. Nicht wenige vernichteten daher ihre persönlichen Dokumente, um ihre Herkunft zu verbergen. Ihre mitgebrachten Russisch-Kenntnisse waren für sie daher ein nur sehr bedingt einsetzbares „kulturelles Kapital“.

2. Das Beispiel der bessarabischen Bauernfamilien zeigt, daß es - mit entsprechender Motivation, Arbeitsmoral und Selbstausbeutung - in der SBZ/DDR durchaus möglich war, auch mit den geringen Betriebsgrößen überlebens- und erweiterungsfähige Einzel-

72 Details hierzu im Bericht von Margarete Romberg „über das Gemeindeleben, Gottesdienste, Amtshandlungen usw. der Stadt Teterow in den Jahren 1945-1946" vom 14. 1. 1949, Evangelisch-lutherisches Pfarramt Teterow für die Landessuperintendentur Malchin (LAS, Inspektionsberichte): Die Stadt Teterow sollte nach dem Abzug der Behörden „laut Nazibeschluß bis zum Äußersten verteidigt werden." Ein Tieffliegerangriff am 30. April löste eine Panik aus, in der die meisten Einwohner aus der Stadt flüchteten. „So war die Stadt am Nachmittag wie ausgestorben, bis auf die vielen Trecks, die aus Richtung Pommern kommend, in ununterbrochenen dichten Zügen alle Straßen sperrten. Erschütternd war es, daß auch das Lazarett, in dem damals viele nicht transportfähige Verwundete lagen, von sämtlichen Ärzten und Schwestern [mit Ausnahme zweier Schwestern sowie der Pastoren] verlassen wurde. [...] Welch schauerliche Nacht! Am schlimmsten für die in der Stadt Zurückgebliebenen und an den See Geflüchteten, die wohl alle den Russen in die Hände fielen. Und so ist es zu verstehen, daß unter dem Eindruck dieses furchtbaren Erlebnisses und in der panikartigen Angst vor den Russen so viele Menschen, auch gute treue Christen, sich das Leben genommen haben. [... Es sind ganze Familien in den See gegangen, haben sich erhängt, erschossen oder vergiftet. [.. . S Schon am zweiten Tag nach dem Einmarsch der Russen begannen die Massenbeerdigungen. Wer das miterlebt hat, vergißt dieses nervenzerreißende, schauerliche Bild sein Lebtag nicht wieder. Sogenannte ,Abschneidekommandos' gingen in die Häuser, um nach Toten, besonders Erhängten, zu suchen. Die so Gefundenen wurden ohne Pietät wie ein Stück Vieh auf unten stehende Lastwagen geworfen und zum Friedhof befördert, wo man sie in Massengräbern beerdigte."

73 Der aus Sarata/Bessarabien stammende Karl Rüb hatte bereits am 2.7. 1945 in Stuttgart ein "Hilfswerk für evangelische Umsiedler" aus Bessarabien und der Dobrudscha begründet. Es war dies in den vier Besatzungszonen die erste Flüchtlingsorganisation überhaupt und zwar zu einer Zeit, in der in der US-Zone noch ein striktes Organisationsverbot galt. Dank seiner guten Verbindungen zur US-Militärregierung, zur Stuttgarter Stadtverwaltung und zum württembergischen Innenministerium gelang es Rüb mit dieser Selbsthilfeorganisation, erste provisorische Unterkünfte für die Umsiedler in Baracken und ehemaligen Fremdarbeiterlagern zu erhalten. Als Gegenleistung mußten sich die Leute für Arbeitseinsätze bereithalten. Die „Organisation Rüb“ konnte aufgrund einer Sondergenehmigung, die sie vom württembergischen Innenministerium erhalten hatte, auch Zuzugsgenehmigungen für "Schwabenumsiedler" ausstellen (insgesamt 10000 bis 15000) und verhandelte schon bald mit Kreisverwaltungen und Landräten in Württemberg über die Aufnahme von Flüchtlingen. Zu den Aktivitäten und zum Selbsthilfekonzept Rübs vgl. Schmidt, „Arbeiten - und nicht verzweifeln. ..", S. 97-99. 
wirtschaften aufzubauen; sie brachten es in den sechziger Jahren sogar zu einem bescheidenen Wohlstand ${ }^{74}$. Durch die rigoristische Kollektivierungspolitik, die zudem das russische Modell mit all seinen Schwächen kritiklos übernahm, ging das hier entstandene Leistungbewußtsein und Identifikationspotential wieder verloren. Eine flexiblere Vorgehensweise, die freiwillige Genossenschaften zwar gefördert, die Existenzbasis leistungsorientierter Einzelwirtschaften vom Typ 1 aber nicht zielgerichtet zerschlagen hätte, wäre im Interesse einer längerfristigen Systemintegration möglicherweise besser geeignet gewesen, die Versorgungsschwierigkeiten in der DDR zu mildern und evidente Fehlsteuerungen in der Landwirtschaftspolitik aufzufangen ${ }^{75}$.

3. Sieben Jahre nach der Wende ist das Erinnerungsbild von der DDR geprägt als eine von der Allgegenwart des Überwachungsstaates durchzogene Gesellschaft. Die Bessarabiendeutschen in den mecklenburgischen Dörfern scheinen demgegenüber - von einigen Repressionen abgesehen - in einer Art „inneren Peripherie“ gelebt zu haben. Die Gründe dafür dürften nicht zuletzt in einem tradierten Politikverständnis zu suchen sein, in dem die staatliche Sphäre von der Lebenswelt in den selbstverwalteten Dörfern weitgehend abgehoben blieb: Bis zur Oktoberrevolution waren die Bessarabiendeutschen unter den Zaren wie unter den Menschewiki loyale russische Staatsbürger gewesen; auch nach der Angliederung Bessarabiens an Rumänien im Jahr 1918 war das Alltagsleben in den Dörfern unterhalb der staatlichen Ebene durch relativ autonome und informelle Strukturen geregelt. Wirtschaftlich waren die Deutschen in den bessarabischen Dörfern in hohem Maße auf sich selbst gestellt. Diese - eher defensive - Abschirmung autonomer Strukturen gegen staatliche Eingriffe ist übrigens nicht gleichzusetzen mit der „Resistenz“ des katholischen Milieus, das mit seiner politischen Repräsentation, der Zentrumspartei, immer auch eine offensive Komponente besaß und den Machtanspruch des Staates prinzipiell in Frage stellte ${ }^{76}$. In den mecklenburgischen Bessarabier-Dörfern konnten nach 1945 offenbar in Jahrzehnten eingeübte Verhaltensweisen und Formen der dörflichen Selbstorganisation reaktiviert und weitgehend unterhalb der Schwelle des offenen Konflikts mit den Organen der Staatspartei SED praktiziert werden. Das Beispiel Grambzow zeigt allerdings, daß die Bessarabier bei ihrem Beharren auf dem „eigenen Weg“ durchaus auch Konflikte mit der Staatsorganen riskierten ${ }^{77}$.

Trotz ihres starken Interesses für die Aufsiedelung der Güter waren die Bessarabiendeutschen - wie übrigens auch andere "Profiteure“ der Bodenreform ${ }^{78}$ - nicht als loyale Klientel für die SED zu gewinnen ${ }^{79}$. Parteilos oder durch die Mitgliedschaft in der

${ }^{74}$ Dieser "Wohlstand" wurde vor allem durch die private Aufzucht und den Verkauf von Vieh erwirtschaftet. Zeitweise war auch eine Erweiterung der bewirtschafteten Fläche durch Hinzupachten von aufgegebenem Land oder Gemeindeländereien möglich; das zusätzliche Land wurde nur zur Hälfte beauflagt.

75 Aus den „Eingriffen in das betriebsorganisatorische Verbundsystem pflanzlicher Primär- und tierischer Sekundärproduktion" seien der DDR eine Reihe gravierender Probleme erwachsen, die in den achtziger Jahren offenkundig geworden seien und "gewichtiger Korrekturen an der Produktionsorganisation der Landwirtschaft" bedürft hätten (vgl. DDR-Handbuch, Bd. 1, S. 785).

76 Vgl. Schmidt, Zentrum oder CDU.

77 Vgl. oben Abschnitt 5.8.

${ }^{78}$ Vgl. dazu Bauerkämper in diesem Band.

79 Bei den Wahlen der Haus-, Straßen- und Bezirksvertrauensleute im Mai 1952 waren zum Beispiel in Schwinkendorf und Langwitz alle aus Bessarabien stammenden Kandidaten parteilos oder DBD-Mitglieder. (Für die 12 Kandidaten aus Grambzow liegen keine Angaben zur Parteizugehörigkeit vor.) Vgl. MLHA, Rat des Kreises, Bd. 39. 
DBD neutralisiert, waren sie aber - ungeachtet tiefer Aversionen gegen die systembedingte Mißwirtschaft und die politische Reglementierung - in ihrer Mehrheit auch nicht offen oppositionell bzw. partiell bereit, sich in die gegebenen Verhältnisse einzufinden.

4. Die Integration der Flüchtlinge in die durch die Bodenreform neugeschaffenen sozialen Verhältnisse auf dem Lande war längere Zeit von strukturellen Asymmetrien begleitet. Auch in den Bodenreformsiedlungen kam es zu Verteilungskämpfen, in denen lokale Interessengruppen im Vorteil waren, und in denen die Flüchtlinge ihren Ansprüchen auf Gleichberechtigung erst allmählich Geltung verschaffen konnten ${ }^{80}$. Zwischen Altund Neubauern gab es ein soziales Gefälle, das sich übrigens auch durch die Vollkollektivierung nicht verwischen ließ. So waren z. B. die Futterreserven der Altbauern häufig auch danach noch groß genug, um ihnen durch die private Aufzucht von Vieh einträgliche Nebenverdienste zu sichern. Diese Asymmetrie wirkte sich auch noch nach der Wende 1989 aus, nach der die Altbauern, die ihr Land zurückerhielten, bessere Chancen gehabt haben dürften, an die Tradition bäuerlicher Familienbetriebe anzuknüpfen als die Neubauern, die ihre Bodenreformflächen allenfalls verpachten (und nur in seltenen Fällen auch mit Gewinn verkaufen) konnten.

Am Beispiel der Bessarabiendeutschen läßt sich zeigen, daß Flüchtlinge und Vertriebene in der DDR - trotz der Tabuisierung der Flüchtlingsthematik und von der DDR-Öffentlichkeit unbeachtet - informelle Substrukturen gebildet haben, die es ihnen ermöglichten, sich in diesen Asymmetrien nicht nur zu behaupten, sondern auch ihre kulturelle Identität zu wahren. „Soziales Kapital“, tradierte Formen der Kooperation und Kommunikation wurden nicht aus rückwärtsgerichteter Nostalgie heraus reaktiviert, sondern benutzt, um in einer veränderten Umwelt einen praktischen Neuanfang zu machen. Vieles deutet darauf hin, daß nicht nur die Bessarabiendeutschen, sondern auch Flüchtlinge aus anderen Herkunftsgebieten in Mecklenburg solche Reserven an „sozialem Kapital“ mobilisierten und jeweils eigene Substrukturen entwickelt haben. (So kommt derzeit etwa ein Beziehungsnetz sudetendeutscher Katholiken in der mecklenburgischen CDU zum Tragen.)

5. Integration ist ein Langzeitprozeß, der sich zumeist über zwei oder drei Generationen vollzieht. Die Studie über die bessarabiendeutschen „Neubauern“ in Mecklenburg hat deutlich gemacht, wie unterschiedlich die Lebenschancen für die jeweiligen Flüchtlingsgenerationen im Aufnahmeland verteilt waren - je nachdem, in welchen Kontexten sie sich bewegten. Es gibt Gewinner und Verlierer; und letztere sind in der älteren Generation, der "Erlebnisgeneration“, die nicht nur den Heimatverlust am schmerzhaftesten empfand, sondern danach auch noch weitere Brüche verkraften und die Hauptlast der Umstellung tragen mußte, besonders zahlreich. Die folgende Generation, die in der kollektivierten Landwirtschaft zumeist keine Perspektive mehr sah, fand ihr Auskommen im allgemeinen nach einer qualifizierten Berufsausbildung jenseits des primären Sektors; sie ist aber heute, nach dem Niedergang von Industriebetrieben und Werften in der ExDDR, z. T. auch durch Arbeitslosigkeit bedroht. Der dritten Generation eröffnen sich nach der Wende 1989 im neuvereinigten Deutschland bisher ungeahnte Karrieren, z. B. als Unternehmer, wenngleich es ihr dabei auch an Kapital und unternehmerischer Erfahrung mangelt. Die Integrationsproblematik, der sich diese Altersgruppe stellen muß, hat sie nun mit den meisten ehemaligen DDR-Bürgern ihrer Generation gemeinsam.

${ }^{80}$ Flüchtlingsfrauen, die in der ersten Nachkriegszeit gemeinsam mit einheimischen Gutsarbeiterinnen auf's Feld gingen, berichten, zwischen ihnen habe sich noch am ehesten ein Solidaritätsgefühl entwickelt. 


\title{
Dagmar Semmelmann
}

\section{Zur Integration aus lebensgeschichtlicher Sicht}

\author{
Eingliederungsverläufe von Flüchtlingen und Vertriebenen \\ in der SBZ/DDR dargestellt am Sonderfall Eisenhüttenstadt
}

Mein Vortrag erwächst aus einem Oral History-Projekt, das ich 1988/89 als Mitarbeiterin des Zentralinstituts für Geschichte der Akademie der Wissenschaften der DDR in Eisenhüttenstadt mit vorwiegend älteren Angehörigen des EKO realisiert habe. Meine damalige Untersuchung hatte nicht die Integration von Flüchtlingen und Vertriebenen zum Thema. Sie war vielmehr in sozialgeschichtliche Forschungen zur qualitativen Entwicklung der Arbeiterklasse in der DDR eingeordnet. Es sollte der Versuch unternommen werden, die Dialektik von Kontinuität, Wandel und Neuprägung sozialer Wahrnehmungs- und Reaktionsweisen bei Angehörigen vornehmlich der Arbeiterklasse in einem staatssozialistischen Industriebetrieb der DDR aus dem Blick von unten zu erfassen und darzustellen. Daß dabei die Wahl des Betriebes auf das EKO fiel, lag - neben forschungspragmatischen Erwägungen - darin begründet, daß es sich hier um einen zu DDR-Zeiten völlig neu entstandenen Betrieb handelte ${ }^{1}$. Inhaltlich ließ ich mich seinerzeit von folgender Überlegung leiten: Wenn es in den 40 Jahren DDR-Gesellschaft einen spürbaren Wandel in den sozialen Einstellungen und Verhaltensweisen der an ihrer Herausbildung beteiligten Menschen in sozialistischer Richtung gegeben hat, dann dürfte ein solcher am ehesten an einem Ort festzustellen sein, wo am „reinsten“, d. h. ohne eine andersartige strukturelle Vorgeschichte, realsozialistische Verhältnisse „objektiviert“ wurden und - zumindest im ersten Jahrzehnt (bis Anfang der sechziger Jahre) - besonders in materieller Hinsicht (Verdienst, Versorgung mit Wohnungen, Lebensmitteln, Sozialeinrichtungen $u$. a.) Vorzugsbedingungen geboten wurden. Wie würde sich in einem solchen Sonderfall der DDR-Geschichte mit dem für ihn charakteristischen Einschnitt in die gesellschaftlichen Basis-Verhältnisse - so gab es in der neuerbauten Stadt im Dienstleistungsbereich und Handel kein privates, sondern nur staatliches und genossenschaftliches Eigentum - die Wechselwirkung zwischen werdenden sozialistischen Strukturen einerseits und den in sie hineinkommenden, sie reproduzierenden und ausgestaltenden Menschen andererseits darstellen?

Unter dieser - hier stark verkürzt wiedergegebenen - konzeptionellen Fragestellung führte ich vom Juni 1988 bis Dezember 1989 über 60 lebensgeschichtliche, halboffene Langzeitinterviews mit EKO-Angehörigen verschiedener Jahrgänge bzw. Generationen. Auf die Jahrgänge 1904 bis 1934 entfallen 40 Personen, und in dieser Gruppe der sogenannten Aufbaugeneration der DDR sind auch 15 Flüchtlinge bzw. Vertriebe-

${ }^{1}$ Vgl. Cerny, Der Aufbau des Eisenhüttenkombinates Ost; ders., Herausbildung sozialistischer Kollektive; ders., EKO. 
$n^{2}$ vertreten. Dieser hohe Anteil der Umgesiedelten (von 31 Prozent) hängt mit der Spezifik des Untersuchungsortes zusammen.

Das ab Sommer 1950 in der Nähe von Fürstenberg an der Oder erbaute Hüttenwerk und die seit 1951 parallel dazu errichtete Wohnstadt für die zuziehenden Betriebsangehörigen und ihre Familien wirkten speziell wegen der relativ gut bezahlten, perspektivenreichen Arbeitsmöglichkeiten und den in Aussicht gestellten günstigen Wohnbedingungen gerade auf ehemalige Heimat-Vertriebene als Magnet, und so wurde Stalinstadt bzw. (seit 1961) Eisenhüttenstadt u. a. auch ein „Sammelbecken“ für aus den verschiedensten Gegenden der DDR, überwiegend aber aus dem (grenznahen) Umland und aus unterschiedlichsten sozialen Milieus kommenden Umgesiedelten, die hier die Chance eines Neuanfangs bzw. Aufstiegs suchten und vielfach auch fanden. Insofern bietet sich diese Region als Untersuchungsfeld für die Vertriebenenproblematik geradezu an. Das war dann auch ein Beweggrund für mich, meine unter der allgemeinen Sozialisations-/Integrationsproblematik geführten Befragungen von 1988/89 unter dem spezifischen Aspekt der Vertriebenenintegration auszuwerten, ohne zusätzliche Befragungen vorzunehmen. Letzteres war deshalb möglich, weil ich in meinen, das gesamte Leben der Befragten umfassenden Interviews natürlich auch in jedem Fall nach diesem gravierenden Kriegsfolgegeschehen gefragt hatte. Zwar ging es mir seinerzeit auch bei den Vertriebenen unter meinen Gesprächspartnern nicht primär um das Einleben und Verwurzeln in die jeweiligen Aufnahmegebiete bzw. ihre zweite Wahlheimat Eisenhüttenstadt; wohl aber interessierte mich ihre Integration in die DDR-Gesellschaft über den gesamten Zeitraum hinweg, also von ihrer Vorgeschichte und ihren Anfängen in der unmittelbaren Nachkriegszeit, über ihre Fortsetzung in der EKO-Periode bis zur Gegenwart.

Die Vertriebenenproblematik stellte sich mir damals als ein wichtiger vorgelagerter, aber nicht detailliert zu verfolgender Aspekt dieser übergreifenden Fragestellung dar. $\mathrm{Da}$ diese jedoch nicht im Mittelpunkt meines damaligen Erkenntnisinteresses stand, sind viele konkrete Aspekte des Einlebens und Fußfassens der Umgesiedelten in den jeweiligen Aufnahmeorten nicht genauer erfragt worden, also unterbelichtet geblieben. Darin liegt ein unkorrigierbarer Mangel dieser Materialbasis. Allerdings kann auf ihrer Grundlage der Versuch unternommen werden, den phasenförmigen Verlauf der Vertriebenen-Integration im biographischen Längsschnitt unter sich grundlegend verändernden Bedingungen aus der Retrospektive der Interviewten nachzuzeichnen, zu analysieren und zu interpretieren. So kann die unter Umständen verzögerte Parallelität und Wechselwirkung von spezifischer Vertriebenen-Integration in das unmittelbare Umfeld am Aufnahmeort der SBZ und allgemeiner Bürger-Integration in die sich bildende DDR-Gesellschaft erfaßt und dabei gezeigt werden, wie sich im Laufe der Zeit die Akzente immer

${ }^{2}$ Mit dieser Begriffsbildung folge ich der in der wissenschaftlichen Literatur üblichen (vgl. Frantzioch, Die Vertriebenen, S. 82f., 271, 275 und v. Plato in: v. Plato/Meinicke, Alte Heimat, S. 83 f.). Dabei fällt es mir aufgrund der „rechtslastigen“ politischen Einfärbung der Begriffe Vertriebene/Vertreibung schwer, sie problemlos-unbekümmert zu verwenden. Deshalb greife ich mitunter auf die in der DDR gebräuchlichen, aber beschönigenden Begriffe Umsiedler/Umsiedlung zurück oder verwende den der Umgesiedelten (vgl. dazu Meinicke, in v. Plato/Meinicke, Alte Heimat, S. 23f.) Für die Benutzung des Vertreibungs-/Vertriebenenbegriffes spricht jedoch die Unfreiwilligkeit und Gewaltsamkeit dieses Vorganges der Aus- und Umsiedlung von Millionen Deutschen nach dem Zweiten Weltkrieg. Hinzu kommt - und das ist für mich ausschlaggebend - daß sich die Betroffenen selbst (und zwar besonders die Ausgewiesenen) wohl mehrheitlich - zumindest nach meiner Interviewerfahrung - als Vertriebene und nicht als Umsiedler bezeichnen, womit sie die erlittene Willkür und inhumane Behandlung kennzeichnen wollen. 
stärker zum allgemeinen Integrationsproblem hin verlagerten, während die Spezifik der Vertriebenensituation in diesem übergreifenden gesellschaftspolitischen Integrationsprozeß nach und nach zurücktrat.

Vertriebenenintegration wird hier folglich als Sonderfall der (allgemeinen) Integration von Angehörigen der Aufbaugeneration in die sich formierende DDR-Gesellschaft behandelt.

Bevor ich zum Thema komme, zunächst noch einige allgemeine Bemerkungen über den Wert der Oral History ${ }^{3}$, speziell von interviewproduzierten mündlichen Quellen für die Flüchtlings- und Vertriebenenforschung ${ }^{4}$ : Lebensgeschichtliche Langzeitinterviews sind unentbehrlich, um das Phänomen Flucht, Vertreibung und anschließende Integration der Betroffenen in die jeweilige(n) Aufnahmegesellschaft(en) in seinen erfahrungsgeschichtlichen wie mentalen Voraussetzungen, seiner einschneidenden, weichenstellenden Dramatik, seinen vielfältigen, zumeist spannungsvollen Verläufen und insbesondere in seinen langfristigen Wirkungen und komplexen Folgen zu erfassen, und damit das Gesamtphänomen in Prozeß und Resultat - wenn auch nur aus subjektiver, retrospektiver Sicht der Betroffenen - in den Blick zu bekommen.

Während schriftliche Quellen und auf ihrer Basis erarbeitete Studien primär die „objektive“, institutionen- und ereignisgeschichtliche Seite dieses Phänomens erfassen, wobei sie oftmals lediglich etwas über einzelne Momente und Zeitabschnitte von Flucht, Vertreibung und anschließender Eingliederung aussagen ${ }^{5}$, erlauben (aktuelle) lebensgeschichtliche Interviews mit Flüchtlingen und Vertriebenen, das (vorläufige) Resultat dieses stufenförmigen Integrationsverlaufes in der Bewertung der Betroffenen (worauf es hier ja besonders ankommt) zumindest annähernd zu erfassen, - und zwar aus der rückgewandten Gegenwartssicht der Erzählenden.

So erweist sich das, was mitunter als Manko der Oral History-Interviews bezeichnet wird, nämlich die verfälschende, verzerrende Sicht von heute auf die Vergangenheit ${ }^{6}$ als Plus, indem es hier ja gerade - wie Alexander v. Plato einmal formulierte - um die Wirkung des Früher auf das Heute bzw. des Heute auf die Konstruktion früherer Erfahrungen geht.

Nun einige Angaben zur Gesamtgruppe der von mir befragten Heimat-Vertriebenen:

Das Sample ist zweigeteilt. Zum einen gehören zu ihm Menschen, die sich nach Kriegsende, aus dem östlichen Oder-/Neiße-Gebiet stammend, in der unmittelbaren Nähe der Grenze in der Hoffnung auf baldige Rückkehr in ihre Heimat niedergelassen hatten; zum anderen sind es Menschen, die es nach dem Krieg, oftmals aus weiter entfernt liegenden, ehemaligen ostdeutschen Gebieten stammend, in die verschiedenen Gegenden der SBZ, vielfach nach Mecklenburg und Thüringen, verschlagen hatte, die dort

${ }^{3}$ Vgl. dazu u. a. Niethammer, Lebenserfahrung; ders., Lebensgeschichte und Sozialkultur, Bd. 3, S. 392-445.

${ }^{4}$ Vgl. u. a. Niethammer, in: Schulze, Flüchtlinge und Vertriebene, S. 258 ff. und 321 f.; v. Plato, in: v. Plato/Meinicke, Alte Heimat, S. $18 \mathrm{ff}$. und S. $94 \mathrm{f}$.

5 Auf diesen Mangel verwies schon Frantzioch unter Bezugnahme auf Helmut Gieser: „Grundsätzlich dominiert, und dies ist nicht nur bei soziologischen Studien zu beobachten, die Abhandlung einer einzelnen Erscheinungsform des sozialen Lebens der Vertriebenen, eines Aspektes des Integrationsprozesses oder aber die additive Aneinanderreihung einer Vielzahl der den Integrationsprozeß konstituierenden Aspekte.“ Frantzioch, Die Vertriebenen, S. 16.

${ }^{6}$ So etwa Prinz, in: Schulze, Flüchtlinge, S. 258 f.; dazu kritisch und richtigstellend, was Oral History an sich und auf diesem Forschungsgebiet zu leisten vermag, Niethammer, in: ebenda, S. 322. 
bis Anfang der fünfziger Jahre noch nicht richtig Fuß gefaßt hatten und die deshalb, vom $\mathrm{EKO}$ angezogen, in diese Region umsiedelten.

Die von mir befragten 15 Heimat-Vertriebenen verteilen sich über die Jahrgänge 1908 bis 1934 , wobei die Jahrgänge 1920 bis 1930 besonders zahlreich vertreten sind, während die älteren und noch jüngeren Jahrgänge seltener vorkommen. Der Frauenanteil ist mit zwei Frauen sehr gering, doch ist er angesichts der Spezifik dieses Industriebetriebes (als einer Männerdomäne) noch vertretbar, zumal in einer Oral-History-Untersuchung ohnehin keine Repräsentativität im soziologisch-statistischen Sinne angestrebt wird und erreichbar ist.

Der sozialen Herkunft wie späteren sozialen Position der Interviewten nach ist das Sample recht inhomogen zusammengesetzt. Meine Gesprächspartner entstammen zumeist Bauern- und Arbeiterfamilien sowie - das aber viel seltener - Angestellten- und Selbständigenmilieus, was annähernd der Zusammensetzung der EKO-Belegschaft der Anfangsjahre entspricht ${ }^{7}$. Kaum einer von ihnen konnte sich vor 1945 eine höhere Schulbildung aneignen und nur wenige einen qualifizierte(re)n Beruf erwerben. Doch durchliefen die meisten von ihnen vorwiegend in den fünfziger Jahren berufliche Qualifizierungsgänge, durch die sie sich zu Meistern, Ingenieuren und Ökonomen mit oder ohne Leitungsfunktionen, (vereinzelt) auch zu hauptamtlichen Partei- und Gewerkschaftsfunktionären entwickelten. Insofern erlangten viele von ihnen - bezogen auf ihr Herkunftsmilieu, ihre Qualifikation und Position vor 1945 - einen mehr oder weniger deutlichen beruflichen und sozialen Aufstieg.

Ihrer Parteimitgliedschaft nach gehörten vor 1945 drei von ihnen der NSDAP an, während neun der 15 Interviewten SED-Mitglieder wurden (zumeist Anfang, Mitte der fünfziger Jahre).

Aus dieser Gesamtgruppe habe ich sechs Personen ausgewählt, um an ihren Lebensgeschichten den Integrationsverlauf in Prozeß und Resultat analysieren und darstellen zu können. Bei diesen sechs Fallbeispielen handelt es sich um die in Erzählform und -inhalt gehaltvollsten, dabei deutlich voneinander (nach Alter, Geschlecht, Herkunftsgebiet, elterlicher und eigener Position, politischer und weltanschaulicher Orientierung und Organisiertheit sowie Flucht- und Vertreibungserfahrungen) differierenden Lebensgeschichten, die dennoch keine Ausnahme-, sondern Durchschnittsfälle darstellen. Schließlich sei noch erwähnt, daß von den sechs ausgewählten Interviewpartnern vier Fluchtund/oder Vertreibungserfahrungen haben, während zwei von ihnen lediglich Heimatvertriebene im definitorisch-juristischen Sinne $\operatorname{sind}^{8}$.

Bei der Analyse und Darstellung der Integrationsverläufe dieser sechs „Fälle“ versuche ich den Zusammenhang zwischen Vertreibungs- und Integrationserfahrung zu erfassen. Dabei gehe ich von folgender, von Lutz Niethammer (in einem Arbeitspapier 1996) formulierten Hypothese aus, „daß die Vertreibungserfahrung selbst und die sich aus ihr ergebende soziale Deklassierung bei den Betroffenen einerseits im Verhältnis zu den Einheimischen besonders starke Tendenzen zum Rückzug zur kulturellen Nische und auch zur Opposition, andererseits vergleichbar starke Tendenzen zu sozialer Bewährung, zur Annahme der Bildungs- und anderer Reform- und Aufbauofferten der DDR bis hin zu

7 Vgl. Cerny, Herausbildung sozialistischer Kollektive, bes. S. $460 \mathrm{ff}$.

${ }^{8}$ Sie sind Vertriebene in dem Sinne, daß sie am 1. 9. 1939 ihren Wohnsitz außerhalb der vier Besatzungszonen östlich von Oder und Neiße hatten, jedoch nach dem Krieg innerhalb der von den Alliierten festgesetzten Grenzen lebten. Vgl. v. Plato in: v. Plato/Meinicke, Alte Heimat, S. 85 f. 
besonderer politischer Einpassungsbereitschaft, wenn diese mit sozialem Aufstieg verbunden war, fördern konnte.“

Im einzelnen ließ ich mich u. a. von folgenden Fragen leiten:

- An welche Spannungen zwischen Alteingesessenen und Umgesiedelten, zwischen Besitzenden und „Habenichtsen“ erinnern sich meine Gewährsleute? Wie belasteten diese die Integration der Neuhinzugekommenen?

- Wie stark hemmten bzw. förderten die vor der Vertreibung erworbenen Persönlichkeitsdispositionen, Wahrnehmungs- und Bewältigungsmuster von Realität das Eingewöhnen in die fremde, unwirtliche Umgebung? Welche Wirkungen gingen dabei von den erworbenen politisch-ideologischen Einstellungen, insbesondere zum NS, für die Integration in die in der SBZ/DDR herrschenden gesellschafts-politischen Verhältnisse aus?

- Wie wirkte sich der jeweilige Grad ihrer Heimatbindung und die unterschiedliche Intensität ihrer Rückkehrhoffnung auf die Integration in das neue Umfeld aus?

- Wie reagierten die Umgesiedelten auf die radikalen sozialökonomischen Umwälzungen in der SBZ im Zuge der Entnazifizierungs- und Enteignungspolitik, z. B. auf die Bodenreform oder andere gravierende Umschichtungen im „Überbau“, etwa auf die Reform im Bildungswesen: Bejahten sie diese als Chance auch für sich selbst oder verhielten sie sich ihnen gegenüber eher reserviert oder gar ablehnend?

- Wie schwierig und reibungsvoll verlief ihre berufliche und soziale Eingliederung in das neue Umfeld, nahmen sie vorhandene Qualifikations- und Aufstiegsangebote an? Und wie verhielten sie sich gegenüber den politisch-organisatorischen Aktivitäts- und Bindungsofferten des jetzt herrschenden Systems (FDJ, SED, betriebliche und kommunale Mitwirkungsformen, u. ̈..)? Waren Vertriebene (im Vergleich zu den Einheimischen) eher eine die DDR-Gesellschaft bzw. ihr politisches System (aktiv) tragende, stabilisierende oder eher eine beides infragestellende, sich dazu (mehrheitlich) reserviert bis ablehnend verhaltende Gruppe?

- Inwiefern und inwieweit gerieten die Vertriebenen durch ihre vielfach gravierenden Positions-Verluste und größere Anstrengungen beim Wiederhoch- und Vorwärtskommen unter stärkeren Unterwerfungs-, Anpassungs- oder Einbindungsdruck (als die oftmals bessergestellten, somit vielfach auch sicherer in sich ruhenden Einheimischen)?

- Inwiefern und inwieweit ist bei ihnen der politisch-ideologische Umerziehungsversuch durch die SED gelungen bzw. nicht gelungen (z. B. hinsichtlich der Bewertung des NS, der Oder-Neiße-Grenze, der Sowjetunion bzw. der „Russen“, der Eigentumsverhältnisse wie überhaupt der sozialistischen Gesellschaftsidee)? Was bewirkte (in diesem Zusammenhang) das Tabuisieren der Vertreibungserfahrung (einschließlich der Unterdrückung selbständiger politisch-organisatorischer Zusammenschlüsse sowie heimatkultureller Äußerungsformen der Vertriebenen) für die „Selbstreinigung“ und Emanzipation der Betroffenen sowie für das politisch-kulturelle Klima der DDR-Gesellschaft?

- Welche Bedeutung messen die Umgesiedelten selbst ihrer Vertreibungserfahrung für ihren weiteren Lebensweg, einschließlich ihrer politisch-ideologischen Einstellung zu? In welcher Hinsicht und wielange hat die Vertreibungserfahrung nachgewirkt? Bezeichnen sich die Befragten selbst als integriert und neu beheimat, und wenn ja, ab wann und wodurch? Welche ungelösten Momente, unaufhebbaren negativen Folgen bleiben für sie dennoch bestehen? Stellt sich für sie in der Retrospektive Vertreibung und nachfolgende Integration eher als unaufhebbarer Verlust, Rückschritt oder mehr als Gewinn, Persönlichkeits-Bereicherung dar? 
- Welchen Einfluß haben die Bedingungen und Verhältnisse im EKO und in Eisenhüttenstadt auf den Integrationsprozeß - im Sinne der Einbindung in die DDR-Gesellschaft und ihr politisches System sowie für die Neubeheimatung der Vertriebenen?

In diesem Rahmen kann ich meine Untersuchungs-Ergebnisse, die in Form von sechs Einzelfallstudien und davon abgehobenen Verallgemeinerungen vorliegen ${ }^{9}$, lediglich an einer Fragestellung demonstrieren. Und zwar frage ich nach dem Verlauf der WiederEingliederung der Umgesiedelten in den Arbeitsprozeß und nach dessen Bedeutung für ibre soziale und politische Integration ${ }^{10}$.

Um eine Vergleichbarkeit meiner „Fälle“ mit den für die SBZ/DDR üblichen zu gewährleisten, werde ich die Integrationsverläufe nur bis 1951/52, d. h. bis zu ihrem Eintritt ins EKO skizzenhaft darstellen und ansatzweise deuten.

Allgemein läßt sich feststellen:

Im Rückblick auf den Zeitraum von der Wohnraumzuweisung im Aufnahmeort (1945/ 46) bis zum Eintritt ins EKO (1951/52) haben alle sechs „Fälle“ (sie stehen für die ganze Gruppe der von mir interviewten Heimatvertriebenen), über Arbeitsaufnahme und feste Eingliederung in den Arbeitsprozeß bzw. weiterführende Qualifizierungsgänge vermittelt, entscheidende Integrationsschritte in ihr neues Umfeld vollzogen, und die meisten von ihnen sind auch schon Bindungen an die offziellen Organisationsformen (FDJ, FDGB, DSF, SED, Frauenausschuß) eingegangen. Dieser bei allen mehr oder weniger rasch, reibungsarm und erfolgreich in Gang gekommene Integrationsprozeß läßt - bei aller individuellen Verschiedenheit in seinen Inhalten, seiner Kontinuität und zeitlichen Erstreckung - einen phasen- oder stufenförmigen Verlauf erkennen. Und zwar lassen sich zwei qualitativ voneinander unterschiedene Phasen ausmachen:

Die erste (relativ kurze) Phase, die sich etwa von 1945/46 bis 1946/47 erstreckt, beginnt mit der offiziellen Aufnahme am Ort, speziell mit der Zuweisung einer Bleibe (gleichviel, ob in einem Umsiedler-Barackenlager oder zur Untermiete) und endet mit dem Übergang zu bzw. Fußfassen in einer regulären Arbeitstätigkeit oder Berufsausbildung. Sie ist eine der Integration vorgelagerte, sie (bestenfalls) vorbereitende Phase und stellt eine mehr oder weniger langwährende, bedrückende „Durststrecke " dar, in der die vielmals schlimmen Flucht- und Vertreibungserlebnisse, aber auch die sich anschließenden Diskriminierungen und Kränkungen beim Herumirren in ostdeutschen Gebieten noch frisch im Gedächtnis sind und die seelische Verfassung der „Neubürger“ weiterhin beeinträchtigen. So dominierten besonders am Beginn dieser Periode, in der tiefste Armut und äußerste materielle Not durchstanden werden mußten, negative Gefühle, auch aggressive, ressentimentgeladene Empfindungen - zumindest bei den Umgesiedelten, die große Verluste an Angehörigen, Besitz, persönlicher Habe, Position, politisch-organisatorischer wie überzeugungsmäßig-emotionaler Bindung hinnehmen mußten oder die aufgrund ihres (höheren) Alters bzw. ihres Familienstandes (geschiedene oder verwitwete Alleinstehende mit Kindern) besonders stark durch die damalige Notsituation belastet waren. Alle erlebten sich in dieser Phase - wenn auch mehr oder weniger frustriert - als Habenichtse oder Nullpunktexistenzen, fühlten sich im neuen Umfeld mehr oder minder stark als fremd, unbehaust, unerwünscht und deklassiert. Manche von ihnen machten zudem die bittere Erfahrung ihres Gedrücktwerdens sowie ihrer

9 Ihre Publikation ist in Vorbereitung.

${ }^{10}$ Vgl. dazu aus ereignisgeschichtlicher Sicht Meinicke, Flüchtlinge, in: v. Plato/Meinicke, Alte Heimat, S. 54-81. 
Ohnmacht gegenüber Willkür von seiten der Besatzungsmacht, aber auch von Einheimischen.

Für diese Phase ist die Konzentration auf das nackte Überleben, das bloße Über-denTag-kommen, ein Von-der-Hand-in-den-Mund-leben charakteristisch. Die Gedanken und Unternehmungen waren (stärker als bei den in der Regel bessergestellten Alteingesessenen) auf das Unmittelbare, die bloße Existenzerhaltung gerichtet; Zukunftspläne wurden nicht gemacht oder lediglich als Rückkehr in die (mehr oder weniger verklärte) Vergangenheit ausphantasiert. Mit allgemeineren Angelegenheiten, politischen Gegenwarts- und Zukunftsfragen gar, beschäftigte man sich so gut wie nicht; eine rationale Auseinandersetzung mit der NS-Vergangenheit und der jetzigen antifaschistischen Gegenwart unter sowjetischem Besatzungsdiktat fand überwiegend nicht statt; nur vereinzelt kam es darüber zu Gesprächen im Kreis von Schicksalsgefährten oder mit guten Bekannten aus dem neuen Umfeld. Das vielfach dennoch (unterschwellig) vorhandene politische Bewußtsein bzw. Empfinden war mehr oder weniger stark ressentimentgeladen bis ablehnend-feindlich gegen die jetzt herrschenden Mächte gerichtet. Stärke und Dauer solcher abweisenden, distanziert-skeptischen bis gegnerischen Haltungen differierten jedoch nach vormaligem Ausmaß der NS-Bindung, Schwere der Vertreibung sowie nach Tempo und Grad der Wiedereingliederung in das gesellschaftliche, speziell örtliche Alltags-/Arbeitsleben.

Obwohl die Vertriebenen mehr oder weniger stark von Rückkehrsehnsucht in die Heimat durchdrungen waren, zwang sie die materielle Notlage dazu, sofort wieder aktiv zu werden. Je nach objektiven Bedingungen am Eingliederungsort und subjektiven Voraussetzungen versuchten sie sich durch „Organisieren“, Schwarzmarkthandel oder sonstige Dienstleistungs-/Tauschgeschäfte, vor allem aber durch Gelegenheitsarbeiten (in der Enttrümmerung, für die Rote Armee, bei Bauern und auf kommunalen Gütern bzw. in Forstbetrieben) über Wasser zu halten. Da die meisten Vertriebenen in Dörfern angesiedelt wurden (nur zwei meiner Gewährsleute ließen sich in einer mittleren bzw. Kleinstadt nieder), blieben ihnen kaum Wahlmöglichkeiten. Vielmehr mußten sie zunächst mit Übergangslösungen (z. B. einem Oberschulbesuch) oder Überbrückungstätigkeiten vorlieb nehmen bzw. regionale, z. T. kriegsfolgebedingte Hilfsarbeiterfunktionen ( $\mathrm{z}$. B. in einem wiedereröffneten Hilfsbergbau oder in Tiefbaubetrieben) annehmen oder auch in der von der Familie übernommenen Neubauernstelle mitarbeiten, bis sich die Chance einer Berufsausbildung bot.

Zwar wurden alle arbeitsfähigen Umgesiedelten relativ rasch wieder in den Arbeitsprozeß eingegliedert, doch keinem von ihnen gelang ein nahtloser, befriedigender beruflicher Start. Die zugewiesenen oder selbst gesuchten Arbeitstätigkeiten trugen primär Not- und Zwangscharakter, und in ihnen wurden - zumindest in der ersten Zeit - auch Kränkungen und Demütigungen erfahren, denen gegenüber man sich vielfach machtund wehrlos fühlte (wie z. B. eine alleinstehende Mutter, die den vom Bauern versprochenen Getreidelohn für mehrtägige Drescharbeit dann doch nicht erhielt). Solche und ähnliche Erlebnisse von Mißachtung und Übervorteilung trugen nicht gerade zur Annäherung zwischen Alteingesessenen und Neubürgern bei, sondern bekräftigten Abneigung und Mißtrauen gegeneinander. Es gab allerdings auch eine entgegenwirkende Tendenz: Durch gemeinsame Arbeitstätigkeit wurden Kontakte geknüpft, mitunter sogar Freundschaften und Partnerschaften eingegangen, wodurch die wechselseitige Abschottung aufgelockert wurde und sich eine Durchmischung beider Seiten anbahnte. Dabei leiteten Freundschaften und vor allem Eheschließungen mit Einheimischen (in zwei meiner sechs 
Fälle vollzogen) eine Zäsur in der Einstellung zum Aufnahmeort und seiner einheimischen Bevölkerung, aber auch zur Arbeits- und Lebensgestaltung ein: Diese bekam nun eine planvollere, zukunftsgerichtete Dimension. Damit begann für diesen Personenkreis eine zweite Phase der Integration.

Aber auch für jene Vertriebenen, die solche privaten, emotional stärkenden Beziehungen nicht eingehen konnten, hatte die Arbeitstätigkeit - neben den angedeuteten frustrierenden, desintegrierenden Wirkungen - auch stabilisierende Effekte: Sie brachte Ablenkung von den Alltagssorgen, baute Fremdheitsgefühle ab, bewirkte unter Umständen im Austausch mit Arbeitskollegen auch die Relativierung des eigenen Leides, erschloß wechselseitige Alltagssolidarität. Das führte aus der Selbst-Isolation heraus, reduzierte Fremdheits- und Verlassenheitsgefühle, ließ einen allmählich zur Ruhe kommen und sich mit seinem Schicksal abfinden. Das Erlebnis, im harten Überlebenskampf bestehen zu können, stabilisierte das Selbstbewußtsein und verstärkte zugleich auch den Willen, sein Los zum Besseren zu wenden, und das wiederum schärfte den Blick für günstigere Existenzmöglichkeiten. So löste man sich allmählich aus der Opfer- und Objektrolle, in die man sich zunächst gedrückt fand, und gelangte nach und nach zu einer größeren Selbstbestimmtheit in der alltäglichen Lebensgestaltung, wobei das natürlich von Fall zu Fall differierte.

Die zweite Phase - zumeist einen fließenden Übergang darstellend - gestaltete sich individuell recht verschieden - je nach subjektiven Voraussetzungen und objektiven Bedingungen in der Aufnahmeregion. Sie begann in einem Fall schon im Herbst 1946 (eingeleitet durch die Aufnahme eines Fachschulstudiums), in der Regel jedoch erst im Laufe des Jahres 1947, im ungünstigsten Fall auch erst 1949. Hier erfolgte das Fußfassen in einer regulären Lohnarbeit oder der Einstieg in die Lehre bzw. in einen Industrieberuf mit Perspektivangeboten oder eine Beförderung in Funktionen innerhalb derselben Arbeitsstelle. Parallel dazu verbesserte oder entspannte sich in einigen Fällen auch die Wohnsituation, wie sich allmählich auch eine Verbesserung der materiellen Lage insgesamt abzeichnete, obwohl der Lebenszuschnitt immer noch äußerst karg und defizitär war. Charakteristisch für diese Phase ist, daß die ausgeübten Arbeitstätigkeiten oder neu aufgenommenen Ausbildungsgänge stärker als in der ersten Etappe auf eigener Entscheidung oder Wahl beruhen.

Allerdings waren die Wahlmöglichkeiten auf dem Arbeits-/Ausbildungssektor seinerzeit nach wie vor recht beschränkt, - zumal für Frauen ohne Beruf, die schon aus diesem Grunde auf traditionelle Frauentätigkeiten zurückgreifen mußten (wie z. B. eine meiner Gesprächspartnerinnen, die zunächst als Strickerin in Heimarbeit für eine private Textilfirma arbeitete, während eine andere, jüngere Frau in dem angenommenen Bauhilfsarbeiterjob verharrte und nur aus Verdienstgründen die Firma wechselte); schwierig blieb die Situation aber auch weiterhin für ungelernte junge Männer, die nicht die gewünschte Lehrstelle fanden, sondern mit einer zeitgemäßen Lehre (vielfach im Baugewerbe) vorlieb nehmen mußten, sowie für ältere Männer, die in ihrem vor dem Krieg erlernten Beruf nicht mehr arbeiten wollten bzw. in der Aufnahmeregion keine entsprechende Arbeitsstelle fanden. Insofern mußten auch sie sich noch eine zeitlang mit unbefriedigenden Hilfsarbeitertätigkeiten begnügen, wobei sie nun aber verstärkt sich bietende Aktivitätsund Aufstiegsmöglichkeiten wahrnahmen.

Mit diesen differierenden Übergängen verringerten sich jedoch in jedem Fall die desintegrierenden, frustrierenden Momente in ihrem noch immer stark mangelbestimmten Alltag; ihr Selbstwertgefühl stieg, und ihre Lebensstimmung wurde hoffnungsvoller. In 
dieser Phase fiel auch oftmals die Entscheidung zum Hierbleiben - gegen die Abwanderung nach Westdeutschland, die vier Männer meiner sechs „Fälle“ bis 1949 mehr oder weniger ernsthaft erwogen hatten, während sich eine Frau von Anfang an zum Hierbleiben entschlossen hatte, zunächst um in unmittelbarer Nähe ihrer Heimat zu bleiben, später wegen ihrer Bindung an die DDR. Das Fußfassen schritt voran - mitunter sogar bis zur Absicht, sich durch Hausbau ständig am Aufnahmeort niederzulassen -, wobei sich alle allmählich mit dem Heimatverlust abfanden, ohne dabei den Rückkehrwunsch schon gänzlich aufgegeben zu haben.

Insgesamt gesehen erweist sich dieser Abschnitt in der Retrospektive als Umschroungsund Aufbruchsphase, aber vielfach auch schon als eine Zeit der Neu-und Umorientierung mit mehr oder weniger großer Schubkraft sowohl für die Integration ins unmittelbare Umfeld als auch (ansatzweise) in die herrschenden, seit Oktober 1949, auch staatlich konstituierten gesellschaftlichen Verhältnisse Ostdeutschlands.

Für bemerkenswert halte ich, daß sich in dieser zweiten Phase bei den Umgesiedelten - trotz partiell weiterbestehender politischer Ressentiments - die Bereitschaft zur organisatorischen Einbindung mit entsprechenden sozialen und teilweise auch politischen Aktivitäten im offiziellen Rahmen erhöhte, was in der Regel mit Perspektivengewinn, beruflicher Förderung und mehr oder weniger deutlichen Aufstiegen in der jeweiligen Arbeitsstelle verbunden war. Man öffnete sich den offiziellen Mitwirkungs- und Bindungsofferten aus Dankbarkeit und/oder einem pragmatischen Aufstiegs-Kalkül, aber auch aus einem virulenten Bedürfnis nach Anschluß an eine emotional wie faktisch haltgebende, zeit- und zukunftsbestimmende Kraft.

Die Integration in den Arbeitsprozeß ist in den meisten Fällen meines Samples von weiterreichender Bedeutung. Daß es offenbar einen engen Zusammenhang zwischen befriedigender Eingliederung in die Arbeitssphäre und (freiwilliger) Einbindung in das gesellschaftspolitische System der SBZ/DDR gab, ist aber nicht nur subjektiv begründet, sondern hängt ebenso sehr mit der Spezifik dieser Verhältnisse zusammen: Anders als in der kapitalistischen, demokratisch-parlamentarisch verfaßten Bundesrepublik mit der ihr immanenten stärkeren Trennung von politischer und ökonomischer Sphäre, von Öffentlichem und Privatem wirkte die antifaschistisch-antikapitalistische „Erziehungsdiktatur" der SBZ/DDR - vermittelt durch die Verstaatlichung der Kernbereiche der Ökonomie und der Durchsetzung der „führenden Rolle“ der SED - primär über die Arbeitsstätten auf ihre Bürger ein, versuchte sie vor allem dort politisch-ideologisch in ihrem Sinne zu beeinflussen bzw. "umzuerziehen“ und in die offiziellen Organisations- und Mitwirkungsformen einzubeziehen. Dieser ab 1948/49 verstärkt durchgesetzte Prozeß bildete den objektiven gesellschaftlichen Hintergrund der konstatierten, sich häufenden subjektiven Einbindungen, indem von ihm aus ein stärkerer Druck in diese Richtung ausging. Die DDR war besonders in den ersten zwei Jahrzehnten eine durchpolitisierte, tendenziell egalitäre Arbeits-Gesellschaft mit politisch-kulturell erzieherischer Intention ihrer Führungsschicht gemäß deren Sozialismusverständnis (sowjetisch-kommunistischer Prägung), die von einem nicht unerheblichen Teil besonders der jüngeren Kriegsteilnehmer- und HJ-Generation angenommen wurde.

Zum Beleg dieser Hypothese seien abschließend einige verallgemeinerte Spielarten von SED-Eintritten angeführt:

Die früheste politische Bindung an die "führende Partei“ vollzog in meinem Sample 1948 ein 1928 geborener, in einer gutsituierten Mittelbauernfamilie in Posen aufgewachsener junger Mann, der aus tradierter deutsch-nationaler Gesinnung zum begeisterten 
HJ'ler geworden war und den es nach schwerer, langanhaltender Flucht- und Vertreibungserfahrung mit der Familie Ende 1945 in ein mecklenburgisches Dorf verschlagen hatte. Dort unter den ärmlichsten Bedingungen lebend und in einer tiefen existenziellen Krise steckend, konzentrierte er sich zunächst, als Forstarbeiter und Gelegenheits-/Freizeit-Dolmetscher tätig, auf das nackte Überleben. Die Befreundung mit einer gutsituierten einheimischen Försterstochter im Sommer 1946 (die er 1948 heiratete) gab ihm emotionalen Auftrieb und den Anstoß für eine zielgerichtete Gestaltung seiner beruflichen Laufbahn. So nahm er im Herbst 1946 - in Anknüpfung an seine frühere Ausbildung zum Landwirt - ein landwirtschaftliches Fachschulstudium in Rostock auf. Nun begann für ihn die Zeit intensiver Beschäftigung mit dem Marxismus und einer intensiven Auseinandersetzung mit der/seiner NS-Vergangenheit sowie den aktuellen politisch-ideologischen Strömungen. Heimatlos geworden, aber bindungs- und mitwirkungsbedürftig geblieben, begab er sich jetzt auf die Suche nach einer neuen ideologisch-weltanschaulichen und politisch-organisatorischen Wiederverwurzelung, - darin unterstützt von einem aus dem Arbeitermilieu stammenden und bereits der SED angehörenden befreundeten Kommilitonen. Von der FDJ-Gruppe im Wohnbezirk angezogen und bald schon als Kulturverantwortlicher seiner FDJ-Organisation aktiv, entschied er sich schließlich, nachdem er sich mit den programmatischen Vorstellungen aller Parteien der SBZ an seinem Studienort vertraut gemacht hatte, 1948 für den SED-Eintritt - in der Annahme, hier jene tragfähige gesellschaftliche Theorie und politisch-organisatorische Heimat gefunden zu haben, in deren Rahmen er nun auch selbst als gut ausgebildeter Fachmann fortschrittsbringend tätig werden könnte. In diesem Sinne, seine Bedenken gegenüber bestimmten Tendenzen in der sich forciert stalinistisch formierenden Partei unterdrückend und sich auf das an ihr Bejahte („die Planbarkeit des Lebens“) fixierend, entfaltete er nach dem Studium auf dem Dorf eine außerordentliche hohe Aktivität, und das so lange, bis er 1951 als stellvertretender Leiter einer MAS auf einem mecklenburgischen Dorf mit der rigiden Anti-Großbauernpolitik seiner staatlichen und parteilichen Vorgesetzten in Kollision geriet, seinen Posten verlor und aus der SED gestrichen wurde. Die früh eingegangene parteipolitische Bindung, von ihm als Neubeheimatung empfunden, erwies sich somit als nicht tragfähig; seine soziale Herkunft und primäre Sozialisation waren wirksamer, als es seine angelernte sozialistische Überzeugung innerhalb eines borniert-dogmatischen, einseitig klassen- und systemkämpferisch orientierten Zusammenhangs sein konnte. Dennoch hielt er an einem Kernbestand seiner angenommenen neuen Überzeugung (nämlich ihren sozialen Intentionen) fest und entschied sich trotz erfahrener tiefer Kränkung und beruflicher Degradation - vornehmlich aus dem Bedürfnis nach Unabhängigkeit auch gegenüber seinen in Westdeutschland lebenden Schwiegereltern und aus Selbstbehauptungsgründen - zum Bleiben in der DDR. Wiederum am existentiellen Nullpunkt angelangt, bemühte er sich in den kommenden Jahrzehnten - und zwar erfolgreich - um einen (erneuten) beruflichen Aufstieg. In seinem mühevoll erworbenen Metallurgenberuf ab 1952 viele Jahre im EKO stark engagiert, blieb er jedoch politisch-organisatorisch ungebunden und verhielt sich distanziert zum politischen System der DDR. Dabei integrierte er sich allerdings faktisch weitgehend in die DDR-Gesellschaft und arrangierte sich eingedenk seiner ab Ende der 60 er Jahre eingenommenen Stellung eines ökonomischen Leiters des EKO-Roheisenwerkes auch politisch (indem er in der BGL seines Betriebes und in Ausschüssen der Nationalen Front aktiv mitarbeitete).

Bei einer zweiten Spielart des SED-Eintritts handelt es sich um einen 1921 in der östlichen Lausitz geborenen, im „stehkragenproletarischen“ Milieu aufgewachsenen, zu- 
nächst NS-begeisterten Kriegsfreiwilligen. Aus französischer Gefangenschaft geflohen, kehrte er über einen Zwischenaufenthalt in Hessen Ende 1946 zu seiner Familie zurück, die es in ein sächsisches Industriedorf verschlagen hatte. Nach der ihn stark deprimierenden offiziellen Aufnahme im Ort (so schickte man ihn, aber nicht die einheimischen Bauernsöhne ins Quarantänelager, obwohl seine Frau schwerkrank war und wenig später starb), fand er auch nur einen mühsamen, unbefriedigenden beruflichen Einstieg als ungelernter Hauer in dem wiedereröffneten Braunkohletagebau am Ort. Unzufrieden mit seiner Arbeits-/Lebens-Situation, ressentimentgeladen und besonders der sowjetischen Besatzungsmacht gegenüber ablehnend eingestellt, wollte er in seinen ersten Zwischenaufenthaltsort in Hessen zurückkehren, zumal er dort ein günstiges Arbeitsangebot auf der Post erhalten hatte. Davon im letzten Moment noch von seiner damaligen Freundin, der Tochter eines einheimischen armen Kleinbauern, abgehalten, entschloß er sich - aus Mitleid und Versorgungsgründen, wie er sagt - zum Bleiben und zur Eheschließung. Dieser Entschluß bewirkte dann auch einen Einstellungswandel gegenüber seiner Berufsarbeit: Ab sofort stellte er sich nicht nur pflichtbewußt auf sie ein, sondern entfaltete darüber hinaus in ihr auch seine ganze Aktivität und sein technisches Geschick. Im Vordergrund seines Denkens und Handelns stand jetzt das schnelle Herauskommen aus der Notsituation und das materielle Vorwärtskommen seiner werdenden Familie. Unter den in der Grube zahlreich beschäftigten schlesischen, aber auch einheimischen Bergleuten wegen seiner Anstelligkeit, Improvisationsgabe und Kollegialität schon bald einen angesehenen Platz einnehmend, erwarb er sich aufgrund seiner Einsatzbereitschaft auch bei seinen Vorgesetzten Wertschätzung und wurde von ihnen alsbald zum ehrenamtlichen BGL-Vorsitzenden (1948) vorgeschlagen (dazu auch von der Belegschaft gewählt) und wenig später (1949) zum Betriebsleiter der Grube befördert. In beiden Funktionen auch im materiellen Interesse der Belegschaft sehr rührig und wegen seiner nunmehrigen Verteilungsmacht (Braunkohle war seinerzeit ein allgemein anerkanntes, weil rares Tauschmittel) auch bei der alteingesessenen Dorfbevölkerung hoch geschätzt, fühlte er sich nun auch wieder voll dazugehörig, also integriert. Auf sein Berufs- und Privatleben konzentriert und pragmatisch auf's Vorankommen orientiert, lag die große Politik außerhalb seines intensiven Interesses. Dennoch trat er 1950, von seinem Vorgesetzten beiläufig daraufhin angesprochen und wie von diesem erwartet, in die SED ein, - ohne zu wissen, aber wohl auch ohne unbedingt wissen zu wollen, worauf er sich da einließ. So vollzog er seinen Parteieintritt in der ignorant-überzeugungslosen, pragmatisch-konformistischen Haltung eines autoritär sozialisierten, sozial engagierten Mitläufers. Doch diese nominell-organisatorische Bindung an die SED entfaltete mit den Jahren im Zuge seines beruflichen und materiellen Vorwärtskommens eine Eigenlogik, so daß er sich - als Meister stark beruflich-sozial engagiert - allmählich auch inhaltlich/innerlich stärker vom Parteistandpunkt vereinnahmen ließ und sich mit den DDR-Verhältnissen nicht nur arrangierte, sondern auch (mehr oder minder) weitgehend mit ihrer staats-sozialistischen Ausrichtung (dem "Geführtwerden" und ihren „sozialen Vorzügen") identifizierte.

Abschließend sei noch eine dritte Art des SED-Eintrittes, die 1951 erfolgte, vorgestellt. Hierbei handelt es sich um einen 1929 geborenen, in einer bessergestellten Arbeiterfamilie in einem ostpreußischen Dorf aufgewachsenen jungen Mann, der - schon als Kind geistig rege und führungsambitioniert, zum begeisterten HJ'ler und Pimpfenführer herangewachsen - nach Beendigung der Volksschule auf eine NS-Lehrerbildungsanstalt delegiert und dort im nationalsozialistischen Sinne indoktriniert worden war. Nach einer strapaziösen Flucht vor der Roten Armee, mit der (seinerzeit vaterlosen) Familie in Thü- 
ringen bei Verwandten untergekommen, geriet er nach dem Zusammenbruch des NS-Regimes in eine tiefe Glaubens- und Bindungs-Krise, die zudem noch dadurch verschärft wurde, daß Vertreter der neuen, antifaschistischen Macht seine Berufspläne - er hatte sich als Neulehrer beworben - vereitelten. Enttäuscht, verbittert und irritiert, überbrückte er den beruflichen Bruch mit einem Oberschulbesuch. Hier die ganze Zeit über in Enttäuschung und Frustration verharrend, verhielt er sich gegenüber den damaligen politisch-ideologischen Angeboten skeptisch bis ablehnend und verweigerte (sogar) die erwartete organisatorische Einbindung in die FDJ. Seine passive, distanzierte Haltung wurde dann auch durch die Schulleitung mit seinem Ausschluß vom Abitur quittiert. Diese neuerliche negative Erfahrung mit Repräsentanten der nun herrschenden Macht wirkte - wie wohl beabsichtigt - als „Denkanstoß“ in konformistischer Richtung. Nach Beendigung der Oberschule arbeitslos geworden, somit verstärkt unter seiner Inaktivität und seinem Ausgeschlossensein leidend, trat er dann doch (noch 1949) der jüngst gegründeten FDJ-Gruppe seines Wohnortes bei, wo er alsbald eine Leitungsfunktion übernahm. Damit hatte er einen ersten Schritt zu seiner politisch-organisatorischen Integration in die DDR-Verhältnisse getan. Der entscheidende Schub in dieser Richtung erfolgte aber wenig später durch seinen Einstieg in das industrielle Berufsleben auf der Maxhütte: Dort zunächst zwar nur als Hilfsarbeiter tätig, waren ihm aber schon bei seiner Einstellung vom damaligen Hüttenchef Qualifizierungs-/Aufstiegsangebote gemacht worden, die dann auch prompt eingehalten wurden. Bereits nach einem Jahr Produktionsarbeit zum Studium auf eine neueröffnete Fachschule für Metallurgie in Unterwellenborn delegiert, faßte er auch wieder Vertrauen in die neue Macht bzw. ihre Funktionäre, und darüber vermittelt öffnete er sich nun auch für die offiziellen politisch-ideologischen Angebote. Hier, im Kreise vielfach älterer, aus den verschiedenen sozialen Milieus und politischen Richtungen kommenden Kommilitonen studierend und lebend, gewann er ein neues Verhältnis zur NS-Vergangenheit und zum jetzt herrschenden, SED-dominierten System. Dabei zog ihn besonders stark die proklamierte Idee einer auf gesellschaftlichem Eigentum beruhenden, folglich ausbeutungsfreien, sozial gerechten und aus eigener Kraft zu schaffenden, materiellen Wohlstand sukzessive für alle (gleichermaßen) gewährleistenden Gesellschaftsordnung an. Dankbar für die ihm jüngst erwiesene Förderung, interessiert an einem beruflichen Aufstieg sowie bindungs- und führungsbedürftig, trat er 1951, noch während des Studiums, der SED bei, - im Glauben, eine gute, gerechte und fortschrittliche "Sache" zu vertreten und in der Absicht, deren Realisierung fortan mit seiner ganzen Kraft zu unterstützen, und zwar im eigenen wie im Interesse der Allgemeinheit. Dabei überließ er die „Liniengebung" vertrauensvoll bzw. gläubig-ignorant „seiner" Parteiführung und beschränkte sich selbst - sich als parteiverbundenen Fachmann verstehend - auf die aktive Umsetzung der jeweiligen „Linie“ in seinem Wirkungskreis. Auf diese Weise, in seinem Rahmen engagiert-kritisch auftretend, dabei Konflikte auch mit Vorgesetzten auf sich nehmend, machte er seinen (recht steilen) Weg, der ihn bis in mittlere Leitungspositionen im EKO führte. Doch Mitte der achtziger Jahre - damals noch in der Funktion des EKO-Hüttenchefs engagiert tätig - stieß auch er an die Systemgrenzen und scheiterte (an diktatorischen Vorgesetzten bzw. an starren, zunehmend erstarrenden Leitungs-Strukturen), ohne sich allerdings vom System und seiner herrschenden Partei abzuwenden, denen er bis zum Schluß - in einem Gefühlsgemisch aus Identifikation, Gewohnheit, Alternativlosigkeit und Angst - „treu“ blieb.

Diese Beispiele von SED-Eintritten belegen, daß ein nicht näher zu quantifizierender Teil der Umsiedler, die auch gute Gründe gehabt hätten, den politisch-ideologischen An- 
geboten der SED kritisch, ja ablehnend gegenüberzustehen, mit einer gewissen Folgerichtigkeit, in spezifischer Verarbeitung ihrer Vertreibungs- und Verlusterfahrungen, sich nicht nur beruflich und sozial engagierte, sondern darüber hinaus - wenn auch individuell sehr verschiedenartig - eine politische Integration in die DDR-Gesellschaft vollzog.

Dieser aus vorliegendem Sample gewonnene hypothetische Schluß schließt die gegenteilige Verallgemeinerung jedoch nicht aus, daß Vertriebene zwar stark (auch stärker als Einheimische) qualifikations- und aufstiegsorientiert gewesen seien, sich aber politisch eher distanziert bis ablehnend dem DDR-System gegenüber verhalten hätten und auch weniger stark von den politisch-ideologischen Umerziehungsbemühungen der SED erreicht worden seien, wie das in Alexander v. Platos Studie zur Vertriebenenintegration von DDR-Bürgern nahegelegt wird. Beide Hypothesen gelten für ihre jeweilige Untersuchungsgruppe. Das verweist allerdings auf die Problematik von qualitativen Untersuchungen, sobald sie ihre Ergebnisse (auch) in quantifizierenden Verallgemeinerungen darbieten. Bevor nicht hinreichend viele (methodisch unterschiedlich herangehende) Detailuntersuchungen vorliegen, sollte man sich besser solcher Verallgemeinerungen enthalten, da sie vermutlich eher den Wert(ungs)horizont des Autors als die Realität der Betroffenen-Gesamtheit widerspiegeln. Jedoch können sie als „Reibefläche“ für weitere Forschungen nützlich sein , - falls ein unvoreingenommenes Klima in der wissenschaftlichen Kommunikation vorherrscht. 